\title{
IL-12 triggers a programmatic change in dysfunctional myeloid-derived cells within mouse tumors
}

\author{
Sid P. Kerkar, ${ }^{1}$ Romina S. Goldszmid, ${ }^{2}$ Pawel Muranski, ${ }^{1}$ Dhanalakshmi Chinnasamy, ${ }^{1}$ \\ Zhiya Yu, ${ }^{1}$ Robert N. Reger, ${ }^{1}$ Anthony J. Leonardi, ${ }^{1}$ Richard A. Morgan, ${ }^{1}$ Ena Wang, ${ }^{3}$ \\ Francesco M. Marincola, ${ }^{3}$ Giorgio Trinchieri, ${ }^{2}$ Steven A. Rosenberg, ${ }^{1}$ and Nicholas P. Restifo ${ }^{1}$ \\ ${ }^{1}$ Center for Cancer Research, National Cancer Institute, NIH, Bethesda, Maryland, USA. ${ }^{2}$ Cancer and Inflammation Program, \\ National Cancer Institute, NIH, Frederick, Maryland, USA. ${ }^{3}$ Infectious Disease and Immunogenetics Section, \\ Department of Transfusion Medicine, Clinical Center and trans-NIH Center for Human Immunology, NIH, Bethesda, Maryland, USA.
}

\begin{abstract}
Solid tumors are complex masses with a local microenvironment, or stroma, that supports tumor growth and progression. Among the diverse tumor-supporting stromal cells is a heterogeneous population of myeloid-derived cells. These cells are alternatively activated and contribute to the immunosuppressive environment of the tumor; overcoming their immunosuppressive effects may improve the efficacy of cancer immunotherapies. We recently found that engineering tumor-specific $\mathrm{CD8}^{+} \mathrm{T}$ cells to secrete the inflammatory cytokine IL-12 improved their therapeutic efficacy in the $\mathrm{B} 16$ mouse model of established melanoma. Here, we report the mechanism underlying this finding. Surprisingly, direct binding of IL-12 to receptors on lymphocytes or NK cells was not required. Instead, IL-12 sensitized bone marrow-derived tumor stromal cells, including CD $11 b^{+} \mathrm{F} 4 / 80^{\text {hi }}$ macrophages, $\mathrm{CD}_{11 b^{+}} \mathrm{MHCII}^{\mathrm{hi}} \mathrm{CD} 11 \mathrm{c}^{\text {hi }}$ dendritic cells, and $\mathrm{CD} 11 \mathrm{~b}^{+} \mathrm{Gr}-1^{\text {hi }}$ myeloid-derived suppressor cells, causing them to enhance the effects of adoptively transferred $\mathrm{CD8}^{+} \mathrm{T}$ cells. This reprogramming of myeloid-derived cells occurred partly through IFN $-\gamma$. Surprisingly, direct presentation of antigen to the transferred $\mathrm{CD8}^{+} \mathrm{T}$ cells by tumor was not necessary; however, MHCI expression on host cells was essential for IL-12-mediated antitumor enhancements. These results are consistent with a model in which IL-12 enhances the ability of CD8 ${ }^{+} \mathrm{T}$ cells to collapse large vascularized tumors by triggering programmatic changes in otherwise suppressive antigen-presenting cells within tumors and support the use of IL-12 as part of immunotherapy for the treatment of solid tumors.
\end{abstract}

\section{Introduction}

Cancer growth, progression, and migration are dependent on inflammatory cells residing within the tumor microenvironment (1). These cells form critical components of a stromal network fostering neovascularization and provide the optimal cytokine and inflammatory support to drive the proliferation of transformed cells into solid masses $(2,3)$. Although these stromal cells are essential for tumor growth, they also possess the inherent capacity to function as APCs. Many studies have highlighted the impairment in activation and maturation of myeloid cells in cancer along with the ability of these cells to create an immunosuppressive environment (4-11).

One of the barriers to obtaining long-term durable responses following the adoptive transfer of $\mathrm{T}$ cells may be immune escape mechanisms present within tumors (12-17). Lymphodepleting chemotherapy regimens are effective in removing regulatory $\mathrm{T}$ cells, but alternatively activated macrophages, immature dendritic cells, and myeloid-derived suppressor cells (MDSCs) also contribute to inhibiting antitumor T cell immunity $(7,18-20)$. Devising methods to alter myeloid-derived cells in situ may represent an attractive strategy when combined with depleting regulatory $\mathrm{T}$ cells.

IL-12 is a hallmark inflammatory cytokine capable of eliciting potent immune responses (21-25). The heterodimeric cytokine is mainly produced by innate immune cells such as dendritic cells, macrophages, and neutrophils and provides a critical bridge between innate and adaptive immunity $(22,26)$. The antitumor

Conflict of interest: The authors have declared that no conflict of interest exists. Citation for this article: J Clin Invest. 2011;121(12):4746-4757. doi:10.1172/JCI58814. effects of IL-12 are thought to involve antiangiogenesis and increased production of IFN- $\gamma$ as well as enhanced lytic abilities of $\mathrm{CD}^{+} \mathrm{T}$ cells, NK cells, and NKT cells to kill tumor targets (27-31). Nevertheless, the mechanisms underlying the antitumor properties of IL-12 remain substantially unelucidated.

We recently showed that engineering pmel- $1 \mathrm{CD} 8^{+} \mathrm{T}$ cells to secrete a functional single-chain IL-12 (Supplemental Figure 1; supplemental material available online with this article; doi:10.1172/JCI58814DS1) obviated the need for exogenous IL-2 and a vaccine and decreased the number of cells needed for the treatment of established B16 melanomas $(32,33)$. This therapeutic model also enabled us to uniquely examine the effects of IL-12 directly at the immunologic synapse, a difficult phenomenon to study when administering IL-12 systemically. Studies by Hans Schreiber's group have highlighted the necessity for high-avidity TCRs in order to recognize cognate antigen cross-presented by tumor stromal cells $(12-14,16)$. In this study, we show that IL-12 triggers a programmatic change in MDSCs, macrophages, and dendritic cells within tumors that enables the licensed recognition of cross-presented antigen without altering TCR avidity. Furthermore, the cross-talk between $\mathrm{T}$ cells and professional APCs in the presence of an acute inflammatory environment triggered by IL-12 within the tumor microenvironment was critical in causing the regression of large established tumors.

\section{Results}

IL-12-induced polarization of adoptively transferred CD $8^{+}$T cells into type I effectors is not necessary for antitumor responses. Based on known mechanisms, we hypothesized that IL-12 secreted in culture polarized 
A
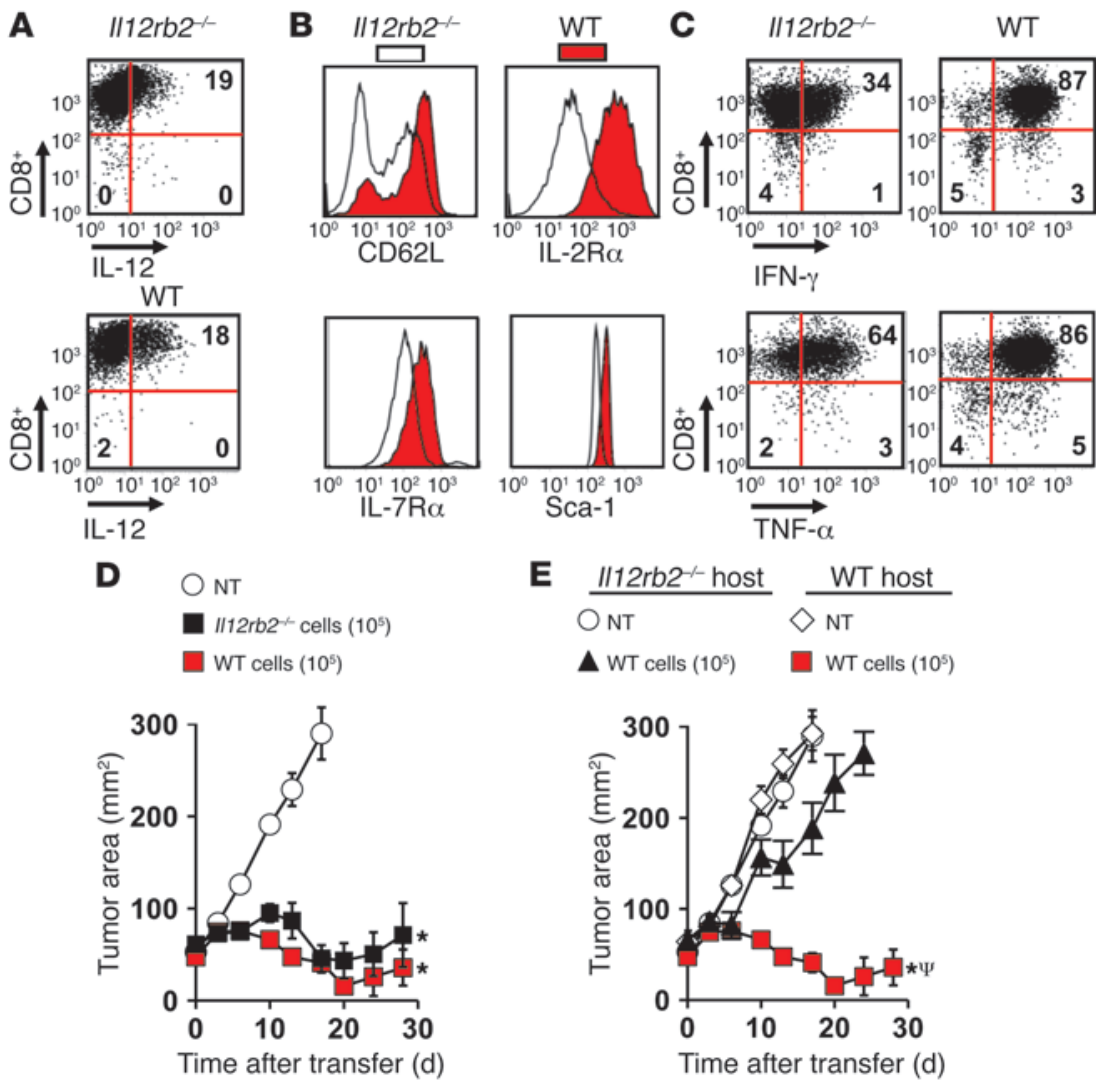
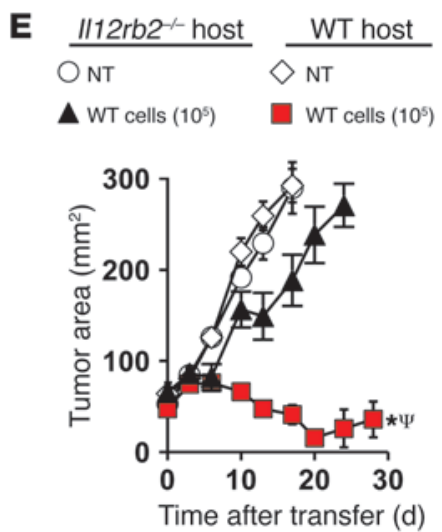

\section{Figure 1}

Antitumor immunity of IL-12-engineered pmel-1 CD8 ${ }^{+} \mathrm{T}$ cells (IL-12 cells) is not dependent on type I self polarization but does require an endogenous response to secreted IL-12. (A) Representative intracellular flow cytometry plot for IL-12 expression in WT or I/12rb2-/CD8 ${ }^{+}$cells. (B) Representative histogram for CD62L, IL-2R $\alpha$, IL-7R $\alpha$, and Sca-1 expression in WT or $1 / 12 r b 2^{-/-}$IL-12 cells. (C) Intracellular staining for IFN- $\gamma$ and TNF- $\alpha$ in WT or $1 / 12$ rb2 $^{-/-}$IL-12 cells stimulated with PMA/ionomycin. All flow cytometry data in A-C are representative of at least 3 independent experiments. Numbers represent percentage of cells in each quadrant. (D) Tumor treatment with $10^{5} \mathrm{WT}$ or $/ 112 \mathrm{rb} 2^{-1-} \mathrm{IL}-12$ cells transferred into sublethally irradiated (5-Gy TBI) C57BL/6 mice bearing 10-day established subcutaneous B16 tumors $(n=5)$. All data are expressed as mean \pm SEM and are representative of 2 independent experiments. ${ }^{\star} P<0.05$, Wilcoxon's rank-sum test compared with no treatment (NT) control. (E) Antitumor immunity of $10^{5}$ WT IL-12 cells transferred into sublethally irradiated WT or $/ 112 \mathrm{rb2}^{-/-}$C57BL/6 mice bearing subcutaneous B16 tumors established for 10 days. All data are expressed as mean \pm SEM and are representative of 2 independent experiments. ${ }^{*} P<0.05$, Wilcoxon's rank-sum test compared with no treatment control; ${ }^{\Psi} P<0.05$, compared with WT IL-12 cells in $/ 112 r b 2^{-/-}$host.

pmel-1 CD8 ${ }^{+} \mathrm{T}$ cells into type I effectors and that these changes were responsible for the improvements in antitumor immunity. To test this hypothesis, we expressed similar levels of IL-12 in WT pmel-1 CD8 ${ }^{+} \mathrm{T}$ cells and Il12rb2--- pmel-1 CD8 ${ }^{+} \mathrm{T}$ cells (Figure 1A). IL-12-engineered pmel-1 CD8 ${ }^{+} \mathrm{T}$ cells (IL-12 cells) possessing functional IL-12 receptors expressed a distinct CD62L $\mathrm{L}^{\text {hi }}$, IL-7R $\alpha^{\text {hi, }}$, IL-2R $\alpha^{\text {hi }}$, and Sca $1^{\text {hi }}$ phenotype not present on $I l 12 r b 2^{-/-}$cells (Figure 1B). Furthermore, WT IL-12 cells were more activated and capable of secreting higher amounts of IFN- $\gamma$ and TNF- $\alpha$ compared with Il12rb2-/- IL-12 cells (Figure 1C). We next adoptively transferred either $1 \times 10^{5} \mathrm{Il} 12 \mathrm{rb} 2^{-/}$or WT IL-12 cells into sublethally irradiated mice ( $5 \mathrm{~Gy}$ ) bearing well-established subcutaneous B16 melanomas and, surprisingly, observed similar levels of antitumor immunity among the cell types (Figure 1D). We then transferred nomas (Figure 3A). Surprisingly, Ifng $/-$ P-TCR/ IL-12 cells induced tumor regression to the same degree as WT P-TCR/IL-12 cells in WT hosts, indicating that IFN- $\gamma$ secretion by transferred $\mathrm{CD}^{+} \mathrm{T}$ cells was not required for antitumor responses (Figure 3A). Within the same experiment, we also transferred WT P-TCR/IL-12 cells into WT or Ifng-/- mice and found that antitumor immunity was significantly impaired in mice unable to produce IFN- $\gamma$ (Figure 3A). These results indicate that the production of IFN- $\gamma$ by endogenous cells was necessary for tumor regression.

We next assessed the importance of IFN- $\gamma$ in imparting a direct effect on endogenous cells by transferring IL-12 cells into sublethally irradiated tumor-bearing Ifngr $/-$ mice and witnessed only a partial impairment in antitumor immunity when host cells were unable to respond to IFN- $\gamma$ (Figure 3B). Taken together, these data illustrate the need for host cells to produce IFN- $\gamma$, but show that 
A

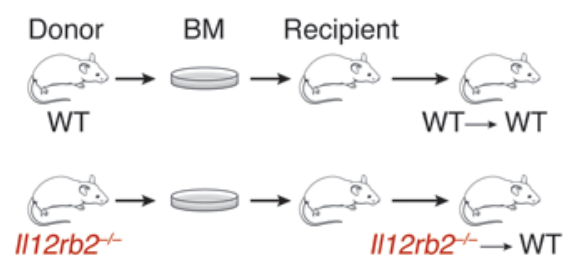

B

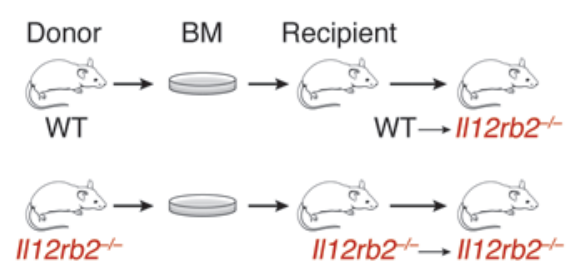

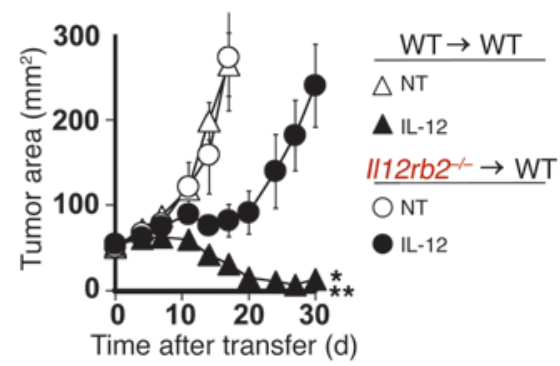

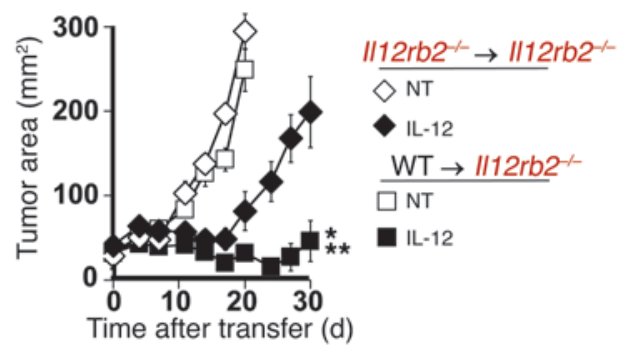

Figure 2

IL-12-dependent sensitization of bone marrow-derived cells is critical for tumor regression. (A) WT C57BL/6 mice were lethally irradiated (6-Gy + 6-Gy TBI) and reconstituted with either WT (WT $\rightarrow$ WT) or $\| / 12 r b 2^{-/-}\left(I / 12 r b 2^{-1-} \rightarrow \mathrm{WT}\right)$ bone marrow. Six weeks after the formation of chimeras, mice ( $n=10 /$ group) were implanted with subcutaneous B16 melanomas, sublethally irradiated (5-Gy TBI), and given $10^{5}$ IL-12 cells after tumors were established for 10 days. Data are expressed as mean \pm SEM and are representative of 2 independent experiments. ${ }^{*} P<0.05$, Wilcoxon's rank-sum test compared with no treatment control; ${ }^{* *} P<0.05$, compared with IL-12 cells into $/ / 12 r b 2^{-/-} \rightarrow$ WT mice. (B) $/ / 12 r b 2^{-1-}$ C57BL/6 mice were lethally irradiated (6-Gy $+6-\mathrm{Gy}$ TBI) and reconstituted with either WT $\left(\mathrm{WT} \rightarrow I / 12 r b 2^{-I^{-}}\right)$or $1 / 12 \mathrm{rb2}^{-{ }^{-}}\left(I / 12 \mathrm{rb2}^{-/-} \rightarrow I / 12 \mathrm{rb2}^{-{ }^{-}}\right)$bone marrow. Six weeks after the formation of chimeras, mice $(n=10 /$ group) were implanted with subcutaneous B16 melanomas, sublethally irradiated, and given $10^{5} \mathrm{IL}-12$ cells after tumors were established for 10 days. Data are expressed as mean \pm SEM and are representative of 2 independent experiments. ${ }^{*} P<0.05$, Wilcoxon's rank-sum test compared with no treatment control; ${ }^{* \star} P<0.05$, compared with IL-12 cells in I/12rb2 $2^{-1-} \rightarrow I / 12 r b 2^{-1-}$ mice.

the requirement for IFN- $\gamma$ receptors on endogenous cells is only partial. These findings suggest that the direct effects of IFN- $\gamma$ on tumor cells may be mechanistically important for antitumor immunity in this model.

IL-12-mediated improvements in antitumor immunity are independent of host T cells, B cells, and NK cells. Based on our previous experiments and published mechanisms of IL-12, we hypothesized that endogenous $\mathrm{CD}^{+}$and NK cells were likely responsible for tumor destruction $(17,19)$. We therefore transferred IL-12 cells into sublethally irradiated tumor-bearing WT or Rag $1^{-/-}$mice that are devoid of endogenous $\mathrm{T}$ and $\mathrm{B}$ cells and found that antitumor responses remained robust in $R a g 1^{-/-}$mice, indicating that endogenous $\mathrm{T}$ or $\mathrm{B}$ cells were not necessary to induce tumor regression (Figure 4A).

We next transferred IL-12 cells into tumor-bearing sublethally irradiated WT or Rag1 1/- mice depleted of NK cells (90\%-95\% NK cell elimination 3 weeks after adoptive transfer) and found that tumor destruction remained robust despite the lack of host $\mathrm{T}$ and $B$ cells and a significant depletion in NK cells (Figure 4B). Based on our previous work indicating that IL-12 enhanced the infiltration of the adoptively transferred $\mathrm{T}$ cells within tumors and the clear benefits gained by IL-12 sensitization of bone marrow cells, we hypothesized that perhaps IL-12 might be altering bone marrow-derived APCs, leading to indirect effects on transferred T cells. We harvested tumor samples 3 and 7 days following the transfer of $1 \times 10^{5}$ mock-transduced cells (mock) or IL-12 cells into sublethally irradiated tumor-bearing Rag1-/- mice depleted of NK cells and found higher numbers of IL-12 cells infiltrating tumors compared with mock cells (Figure 4C).

To visualize infiltrating $\mathrm{T}$ cells within tumors, we captured immunofluorescent confocal images (transferred $\mathrm{T}$ cells, thy $1.1^{+}$green; blood vessels, $\mathrm{CD} 31^{+}$red) from tumor sections 7 days following cell transfer into sublethally irradiated mice and observed thy $1.1^{+}$transferred $T$ cells infiltrating the extravascular space of tumors treated with IL-12 cells, but not mock cells (Figure 4D). We also subjectively witnessed disruptions in the vascular integrity of tumors in mice treated with IL-12 compared with mock cells, although this observation was more an association than a mechanistic finding. Thus, IL-12 within the tumor microenvironment indirectly led to the increased local proliferation of adoptively transferred tumor antigen-specific T cells. This was unexpected, but completely consistent with our data showing that IL-12 did not act directly on transferred $\mathrm{T}$ cells and instead sensitized bone marrow-derived cells independently of host T, B, and NK cells to indirectly enhance the ability of transferred $T$ cells to infiltrate tumors.

An inflammatory gene signature and increased antigen processing and presentation within tumors treated with $I L-12$-engineered $C D 8^{+} T$ cells. To understand how IL-12 triggered tumor regression, we performed whole transcriptome analysis of tumor samples from mice 3 and 7 days following treatment with IL-12 cells or mock cells $(24,28)$. We examined select genes encoding for cytokines, chemokines, chemokine receptors, inflammatory mediators, and costimulatory molecules and observed an over 10-fold increase in the expression for IL-1 $\beta$, S100a8, and S100a9 from tumors of mice 3 days following treatment with IL-12 compared with mock cells (Table 1). Interestingly, we also observed an increase in gene expression for Nlrp 3 and Nlrc5 within IL-12-treated tumors, indicating a possible role for inflammasome formation in antitumor immunity.

Overall, we found 407 transcripts differentially expressed on days 3 and 7, with 360 genes upregulated and 47 genes downregulated (Figure 5A; fold change $[\mathrm{FC}]>2, P$ value with false discovery rate $[\mathrm{FDR}]<0.05, n=4)$. We performed an unbiased gene-ontology enrichment analysis, and the highest enrichment score was assigned to immune system processes in tumors treated with IL-12 compared with mock cells (Supplemental Figure 2). Under the immune system category, pathway analysis identified antigen processing and presentation as the most differentially increased pathway (Figure 5B), and mRNA levels for several genes such as tap1, tap2, tpn, clip, Imp2, Imp7, H2-Ab1, H2-Q6, H2-Aa, H2-DMa, H2-K1, $H 2-D 1$, and $H 2-A b 1$ were at least 2-fold higher in IL-12 compared with mock-treated tumors (Figure 5C). Additionally, the most 


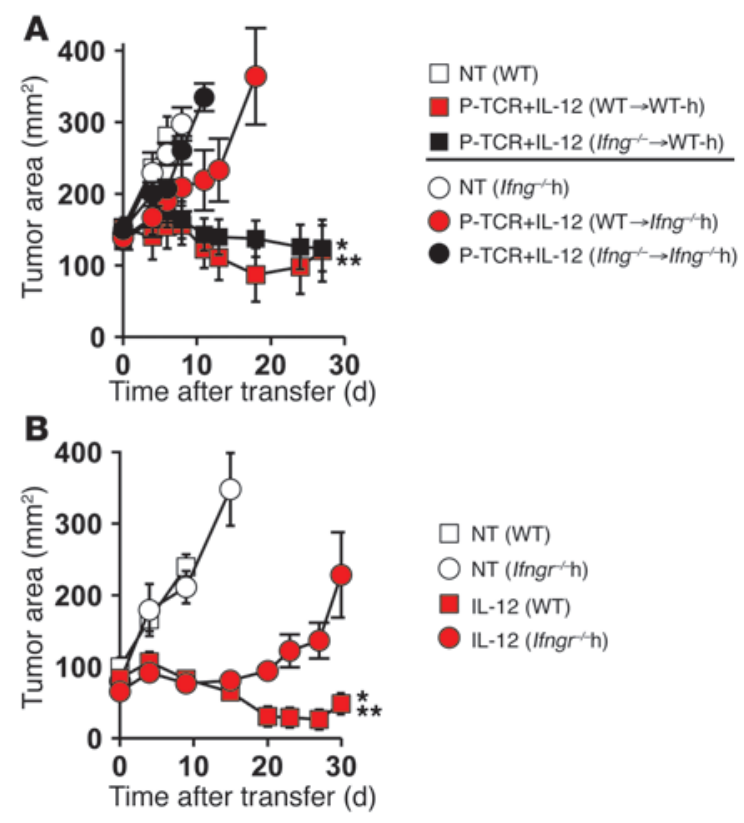

differentially expressed transcript was Ifng (>62-fold) along with mRNA levels for genes commonly found in effector T cells ( $\mathrm{Gzmb}$, Il2ra, Gzma; Figure 5D).

We confirmed the transcript level by real-time PCR assays for 2 known inflammatory mediators and found significantly higher expression of IL-10 and iNOS from tumors of mice treated with IL-12 compared with mock cells (Supplemental Figure 3). We also noted temporal changes within tumors, as 2,776 genes were differentially expressed between days 3 and 7 in tumors treated with IL-12 cells (Supplemental Figure 4). Although these results highlighted the dynamic nature of the tumor microenvironment prior to the regression of established lesions, analyzing gene transcripts differentially expressed consistently on both day 3 and day 7 provided valuable mechanistic insights. Given that tumor rejection involved IL-12-mediated sensitization of bone marrow-derived cells and that host T cells, B cells, and NK cells did not appear to be involved, data generated by the whole transcriptome analysis pointed toward antigen processing and presentation as an important mechanistic pathway differentially expressed in mice treated with IL-12 compared with mock cells.

Antitumor immunity of IL-12 cells is dependent on the functional reprogramming of myeloid-derived cells in situ to cross-present natural tumor antigens. Based on our previous experiments, we hypothesized that IL-12 may have an impact on the antigen-presenting capabilities of bone marrow-derived stromal cells residing within tumors. We therefore looked for IL-12 receptor $\beta 2$ (Il12rb2) expression in single-cell suspensions of whole tumors and found that the majority of cells capable of functionally responding to IL-12 were indeed

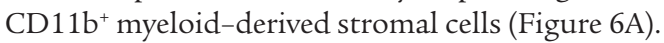

We next analyzed single-cell tumor suspensions from mice 1 week following treatment with mock or IL-12 cells and analyzed $\mathrm{PI}^{-}, \mathrm{CD}^{-}, \mathrm{B} 220^{-}, \mathrm{NK} 11^{-}$, and $\mathrm{CD} 11 \mathrm{~b}^{+}$myeloid-derived cells. Tumor-infiltrating myeloid cells from mice treated with IL-12 cells compared with mock cells appeared markedly different based on forward and side scatter on flow cytometric analysis (Figure 6B). To assess whether we had truly reprogrammed tumor-infiltrating myeloid-derived cells in situ, we performed

\section{Figure 3}

IL-12-induced IFN- $\gamma$ production and sensitization by host cells are partially required for antitumor immunity. (A) Antitumor immunity of $2.5 \times 10^{5}$ WT or Ifng ${ }^{-1-}$ CD $8^{+}$T cells expressing the P-TCR and IL-12 transferred into sublethally irradiated (5-Gy TBI) C57BL/6 mice ( $n=5 /$ group) bearing subcutaneous B16 tumors established for 10 days. In the same experiment, $2.5 \times 10^{5} \mathrm{WT} C D 8^{+} \mathrm{T}$ cells expressing the P-TCR and IL-12 were adoptively transferred into sublethally irradiated WT or lfng ${ }^{-/-}$C57BL/6 mice (Ifng ${ }^{-/-h} ; n=5$ ) bearing subcutaneous B16 tumors established for 10 days. All data are expressed as mean \pm SEM and are representative of 2 independent experiments. ${ }^{*} P<0.05$, Wilcoxon's rank-sum test compared with no treatment control; ${ }^{\star \star} P<0.05$, compared with P-TCR + IL-12 (WT > Ifng ${ }^{-1-h}$ ). (B) Antitumor immunity of $10^{5} \mathrm{IL}-12$ cells following transfer into sublethally irradiated WT or Ifngr ${ }^{-1-}$ C57BL/6 recipient mice (Ifng $r^{-1-h}$ ) bearing subcutaneous B16 tumors established for 10 days. All data are expressed as mean \pm SEM and are representative of 2 independent experiments. ${ }^{*} P<0.05$, Wilcoxon's rank-sum test compared with no treatment control; ${ }^{* \star} P<0.05$, compared with IL-12 cells in Ifngr ${ }^{-1}$ h mice.

a flow cytometry-based cell sort of $\mathrm{PI}^{-}, \mathrm{CD}^{-}, \mathrm{B} 220^{-}, \mathrm{NK} 11^{-}$, and $\mathrm{CD} 11 \mathrm{~b}^{+}$cells from established tumors of treated mice and carried out PCR-based arrays for transcripts common to APCs. We observed an over 8-fold increase in transcript levels for Ifng, Il2, Ilsra, Ccl11, and Ccl20 in 2 independent experiments from myeloid-derived cells isolated from multiple pooled tumors treated with IL-12 over mock cells (Supplemental Figure 5). Interestingly, we also measured over 4-fold increases in mRNA for B2m (Supplemental Figure 5) and recorded higher expression of $\mathrm{H}-2 \mathrm{D}^{\mathrm{b}}$ on $\mathrm{CD} 11 \mathrm{~b}^{+}$myeloid-derived cells from tumors of mice treated with IL-12 over mock cells (Figure 6C).

To understand the functional importance of increased levels of MHC class I, we transferred IL-12 cells into sublethally irradiated tumor-bearing WT, B2m-/- (MHC class I deficient), or IAb-/- (MHC class II deficient) mice. We observed a significant impairment in antitumor immunity in mice lacking MHC class I but not MHC class II (Figure 6D). Importantly, untreated tumors grew at an identical pace in mice of all strains. These results clearly implicated the need for in vivo cross presentation for successful antitumor responses, an interesting finding given that we transferred cells that were highly activated in vitro and the tumors grown on mice were unmanipulated and fully capable of being directly recognized.

To further assess the importance of in vivo cross presentation, we transferred IL-12-engineered pmel-1 Ly $5.1^{+}\left(I L-12^{\text {P-Ly5.1 }}\right)$ gene-marked $\mathrm{CD}^{+} \mathrm{T}$ cells and open-repertoire IL-12 engineered thy $1.1^{+}\left(I L-12^{\text {OR-Thy1.1 }}\right)$ gene-marked $\mathrm{CD}^{+} \mathrm{T}$ cells into the same WT or $B 2 \mathrm{~m}^{-1-}$ mouse (Figure $6 \mathrm{E}$ ). We observed an increase in the proliferation of activated antigen-specific IL-12 $2^{\text {P-Ly }} 5.1$ in WT mice compared with $B 2 \mathrm{~m}^{-/-}$mice. Notably, we saw no IL-12 $2^{\text {P-Ly } 5.1}$ within

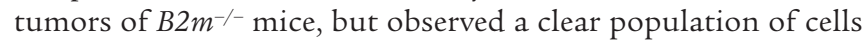
within tumors of WT mice. Furthermore, we observed no defects in the longevity of open-repertoire IL-12 ${ }^{\text {OR-Thy1.1 }} \mathrm{CD}^{+} \mathrm{T}$ cells in $B 2 m^{-1-}$ mice compared with WT mice (Figure $6 \mathrm{E}$ ). To visualize infiltrating $\mathrm{T}$ cells within tumors in WT compared with $B 2 \mathrm{~m}^{-/-}$mice, we captured immunofluorescent confocal images (transferred $\mathrm{T}$ cells, thy $1.1^{+}$green; blood vessels, $\mathrm{CD} 31^{+}$red) from tumor sections 7 days following the transfer of $1 \times 10^{5}$ IL-12 cells into sublethally 

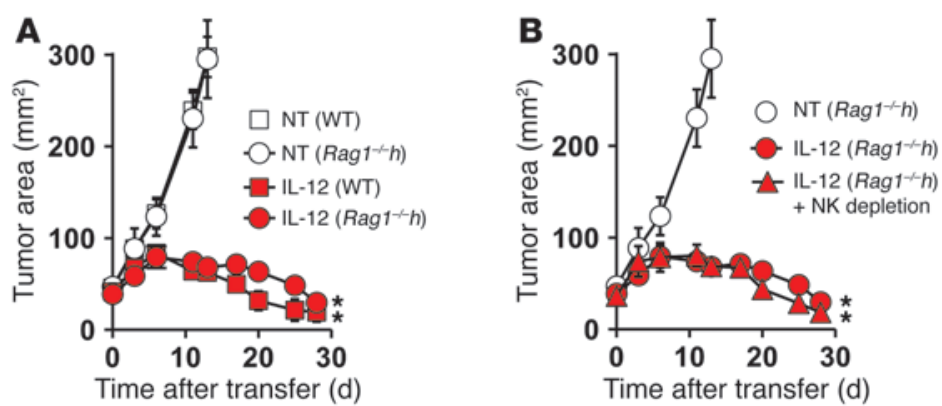

C
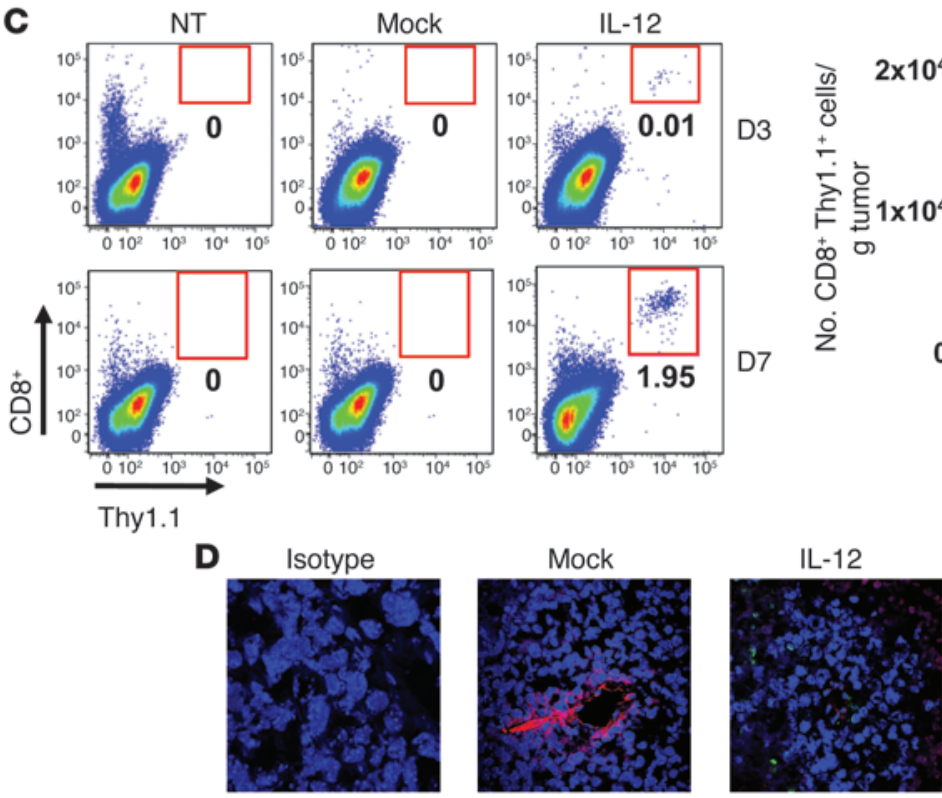

Mock

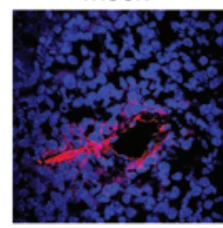

Tumor

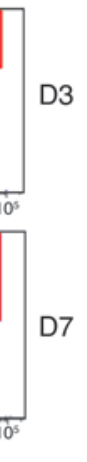

Day 3

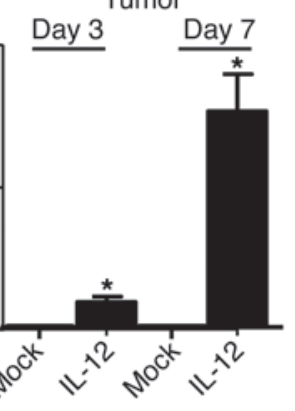

ing (8 hours) a 5-Gy total body irradiation (TBI) preconditioning regimen and found a panoply of myeloid-derived cell populations residing within tumors. Due to the redundancy of cell-surface markers between many of the myeloidderived cell subpopulations, we used highly multicolored flow cytometry to analyze unique subpopulations of cells within tumors. We first created single-cell suspensions of established B16 tumors and created a live gate by excluding cells staining positive for the vivid fixable violet live/dead stain.

We analyzed all endogenous cells within tumors by gating on CD $45^{+}$cells and found that the majority of endogenous cells were of myeloid origin and stained positive for CD11b (Figure 7A). The $\mathrm{CD}_{4} 5^{+} \mathrm{CD} 11 \mathrm{~b}^{-}$population consisted mostly of lymphocytes, with a small fraction of NK cells (data not shown). Within the $\mathrm{CD}_{4} 5^{+} \mathrm{CD} 11 \mathrm{~b}^{+}$gate, we observed a distinct population of dendritic cells that stained for CD11c and I-A ${ }^{b}$. We next analyzed the CD $45^{+} \mathrm{CD} 11 \mathrm{~b}^{+} \mathrm{CD} 11 \mathrm{c}^{\mathrm{lo}}$ population and observed a clear population of macrophages that stained positive for $\mathrm{F} 4 / 80$ $\left(\mathrm{CD} 45^{+} \mathrm{CD} 11 \mathrm{~b}^{+} \mathrm{CD} 11 \mathrm{c}^{\mathrm{lo}} \mathrm{F} 4 / 80^{\mathrm{hi}}\right)$. We then evaluated the fraction of myeloid cells that were $\mathrm{CD} 45^{+} \mathrm{CD} 11 \mathrm{~b}^{+} \mathrm{CD} 11 \mathrm{c}^{\mathrm{lo}} \mathrm{F} 4 / 80^{\mathrm{lo}}$ and detected distinct populations of cells expressing Ly6C and Ly6G. These cells, commonly characterized as MDSCs (ref. 34), represent a heterogeneous population of cells from monocytic (MDSC-M) and granulocytic (MDSC-G) origins (Figure 7A). Within B16 tumors, we observed a distinct population of $\mathrm{CD} 45^{+} \mathrm{CD} 11 \mathrm{~b}^{+} \mathrm{CD} 11 \mathrm{c}^{\mathrm{lo}} \mathrm{F} 4 /$

irradiated WT or $B 2 m^{-1-}$ mice and observed thy $1.1^{+}$transferred T cells infiltrating the extravascular space of tumors in WT but not $B 2 m^{-1-}$ mice (Figure 6F). Thus, IL-12 secreted by tumor-specific $\mathrm{CD}^{+} \mathrm{T}$ cells triggered the functional reprogramming of in situ myeloid-derived cells, promoting the cross presentation of natural tumor antigens that enabled transferred $\mathrm{T}$ cells to infiltrate tumors and induce the regression of well-established lesions.

Characterization and antigen-presenting capabilities of myeloid-derived subpopulations within tumors. To analyze myeloid-derived stromal populations within tumors in a more detailed manner, we performed multicolor flow cytometry on single-cell suspensions from well-established subcutaneous B16 tumors shortly follow- $80^{\mathrm{lo}} \mathrm{Ly} 6 \mathrm{C}^{\text {hi }} \mathrm{Ly} 6 \mathrm{G}^{\text {lo }}$ cells of monocytic origin that we categorized as MDSC-M. There also existed a clear population of CD $45^{+} \mathrm{CD} 11 \mathrm{~b}^{+}$ CD $11 c^{\text {lo }}$ 4 $/ 80^{\text {lo }}$ Ly $6 \mathrm{C}^{\text {mid-hi }}$ Ly6 $6 \mathrm{G}^{\text {hi }}$ cells that we characterized as granulocytic in origin (MDSC-G), although this categorization is still a matter of debate (Figure 7A and ref. 35). Thus, bone marrow-derived myeloid cells composing the tumor stroma are a heterogeneous population of phenotypically distinct immune cells.

We next sought to assess the ability of tumor-residing myeloid populations to stimulate the division and activation of $\mathrm{CD}^{+} \mathrm{T}$ cells. Single-cell suspensions of well-established B16 melanomas from mice treated with IL-12 or mock cells were sorted by flow cytometry for macrophages, dendritic cells, and MDSCs (sorting strategy 
Table 1

Select genes significantly differentially expressed within tumors of mice treated with IL-12-engineered CD8 ${ }^{+} \mathrm{T}$ cells

\begin{tabular}{|c|c|c|c|}
\hline \multirow{2}{*}{ Gene symb } & \multirow[b]{2}{*}{ Gene name } & \multicolumn{2}{|c|}{ FC IL-12/mock } \\
\hline & & Day 3 & Day 7 \\
\hline \multicolumn{4}{|c|}{ Cytokines, chemokines, and chemokine receptors } \\
\hline$/ 11 b$ & Interleukin-1 $\beta$ & 12.26 & 1.28 \\
\hline Cxcr6 & Chemokine (C-X-C motif) receptor 6 & 10.85 & 7.52 \\
\hline Cxcl9 & Chemokine (C-X-C motif) ligand 9 & 5.58 & 7.46 \\
\hline Ccrl2 & Chemokine (C-C motif) receptor 2 & 5.46 & 1.76 \\
\hline $1 / 1 a$ & Interleukin-1 $\alpha$ & 4.87 & 1.03 \\
\hline Cxcl10 & Chemokine (C-X-C motif) ligand 10 & 4.39 & 8.11 \\
\hline Ccl4 & Chemokine (C-C motif) ligand 4 & 4.59 & 1.04 \\
\hline Cor1 & Chemokine (C-C motif) receptor 1 & 4.32 & 1.24 \\
\hline Ccl5 & Chemokine ( $\mathrm{C}-\mathrm{C}$ motif) ligand 5 & 3.58 & 2.57 \\
\hline Tnf & Tumor necrosis factor & 3.45 & 1.49 \\
\hline $\mathrm{Cxcl3}$ & Chemokine ( $\mathrm{C}-\mathrm{X}-\mathrm{C}$ motif) ligand 3 & 3.34 & -1.34 \\
\hline $\mathrm{Ccl} / 8$ & Chemokine (C-C motif) ligand 8 & 3.27 & 3.55 \\
\hline CCl25 & Chemokine (C-C motif) ligand 25 & -1.68 & 1.05 \\
\hline Ccl17 & Chemokine (C-C motif) ligand 17 & -1.56 & 1.38 \\
\hline \multicolumn{4}{|c|}{ Inflammatory mediators } \\
\hline S100a8 & S100 calcium binding protein A8 & 18.05 & -1.10 \\
\hline S100a9 & S100 calcium binding protein A9 & 17.19 & 1.02 \\
\hline Saa3 & Serum amyloid $\mathrm{A} 3$ & 8.04 & 2.19 \\
\hline Nos2 & Nitric oxide synthase 2, inducible & 8.64 & 4.58 \\
\hline NIrc5 & NLR family, CARD domain containing 5 & 2.91 & 8.97 \\
\hline NIrp3 & NLR family, pyrin domain containing 3 & 2.68 & 1.12 \\
\hline Aim2 & Absent in melanoma & 2.31 & 2.38 \\
\hline \multicolumn{4}{|c|}{ Costimulatory molecules } \\
\hline Icos & Inducible T cell costimulator & 6.89 & 3.21 \\
\hline $\begin{array}{l}\text { Tnfrsfg } \\
(4-1 B B)\end{array}$ & $\begin{array}{l}\text { Tumor necrosis factor receptor } \\
\text { superfamily, member } 9\end{array}$ & 8.47 & 2.47 \\
\hline $\begin{array}{l}\text { Tnfrsf4 } \\
(0 X-40)\end{array}$ & $\begin{array}{l}\text { Tumor necrosis factor receptor } \\
\text { superfamily, member } 4\end{array}$ & 5.75 & 2.22 \\
\hline $\begin{array}{l}\text { Tnfrsf18 } \\
\text { (GITR) }\end{array}$ & $\begin{array}{l}\text { Tumor necrosis factor receptor } \\
\text { superfamily, member } 18\end{array}$ & 5.72 & 2.14 \\
\hline Slamf7 & Slam family member 7 & 4.44 & 4.09 \\
\hline Slamf8 & Slam family member 8 & 3.44 & 3.79 \\
\hline Icam1 & $\begin{array}{l}\text { Intercellular adhesion } \\
\text { molecule } 1 \text { (CD54) }\end{array}$ & 2.46 & 3.08 \\
\hline
\end{tabular}

depicted in Supplemental Figure 6). These different populations were then cocultured with CFSE-labeled $\mathrm{CD}^{+} \mathrm{T}$ cells isolated from untouched splenocytes of P-TCR Tg mice in a 10:1 ratio of T cells to APCs. Myeloid-derived populations isolated from B16 tumors of mice treated with mock cells failed to induce the division of naive pmel-1 CD8 ${ }^{+} \mathrm{T}$ cells (Figure 7B). In striking contrast, macrophages, dendritic cells, and MDSCs from B16 tumors in mice treated with IL-12 cells stimulated the in vitro division and activation of $\mathrm{CD}^{+}$ $\mathrm{T}$ cells (Figure $7 \mathrm{~B}$ ). These results indicate that IL-12 triggered a programmatic change in the major professional APC populations present within tumors, although IL-12 sensitization of MDSCs appeared to be the most potent in stimulating $\mathrm{CD}^{+} \mathrm{T}$ cells.

Recognition of cross-presented tumor antigen by $I L-12$-expressing $C D 8^{+} T$ cells is sufficient to induce tumor regression. We sought to further examine the importance of IL-12 in triggering the recognition of cross-presented antigen by antitumor $T$ cells. We developed a model to examine the effects of in vivo cross presentation by implanting Cloudman S91 melanomas $\left(\mathrm{H}-2^{\mathrm{d}}\right)$ on $\mathrm{C} 57 \mathrm{BL} / 6 \times \mathrm{DBA} F 1\left(\mathrm{H}-2^{\mathrm{b} / \mathrm{d}}\right)$ mice followed by the adoptive transfer of pmel- $1 \mathrm{CD}^{+} \mathrm{T}$ cells $\left(\mathrm{H}-2^{\mathrm{b}}\right)$. To confirm the MHC restriction of our tumor lines, we added IFN- $\gamma$ in vitro for 48 hours and witnessed an expected increase in $\mathrm{H}-2^{\mathrm{b}}$ expression in $\mathrm{B} 16$ melanoma cultures and an increase in $\mathrm{H}-2^{\mathrm{d}}$ expression in Cloudman S91 melanoma culture lines (Figure 8A). These results confirmed the identities of the tumors used in MHC mismatch experiments.

To test the capacity of IL-12 cells to trigger killing of MHC mismatched tumors incapable of direct antigen presentation, we implanted Cloudman melanomas $\left(\mathrm{H}-2^{\mathrm{d}}\right)$ in C57BL/6 × DBA F1 $\mathrm{H}-2^{\mathrm{b} / \mathrm{d}}$ mice and transferred IL-12 or mock cells $\left(\mathrm{H}-2^{\mathrm{b}}\right)$ into sublethally irradiated mice. We observed the regression of large established tumors following the transfer of IL-12 compared with mock cells (Figure 8B). The presence of IL-12 had a significant impact on improving the antitumor immunity of tumor-specific $\mathrm{CD}^{+}$ $\mathrm{T}$ cells, indicating that IL-12 triggered changes within tumors to enhance the cross presentation of antigens in vivo.

We sought to assess the differential impact of transferred IL-12expressing cells on subpopulations of myeloid-derived cells capable of cross-presenting tumor-associated antigens for recognition by $\mathrm{CD}^{+} \mathrm{T}$ cells. We identified populations of myeloid-derived cells (macrophages, dendritic cells, MDSC-M, and MDSC-G) residing within Cloudman S91 melanomas (Figure 8C). Unlike the tumor cells in which they reside, the myelomonocytic cells from C57BL/6 $\times$ DBA F1 mice expressed both $\mathrm{H}-2^{\mathrm{b}}$ and $\mathrm{H}-2^{\mathrm{d}}$ and could therefore be recognized by IL- 12 cells specific for gp $100_{25-33}$ in the context of $\mathrm{H}-2^{\mathrm{b}}$. We examined the presence of these cells within tumors 10 days following the adoptive transfer of either IL-12 or mock cells. Just prior to a major drop in tumor size, 10 days following the transfer of IL-12 cells, we observed a sudden decrease in $\mathrm{CD} 11 \mathrm{~b}^{+} \mathrm{F} 4 / 80^{\mathrm{hi}}$ macrophages, $\mathrm{CD} 11 \mathrm{~b}^{+} \mathrm{CD} 11 \mathrm{c}^{\text {hi }}$ dendritic cells, and $\mathrm{CD} 11 \mathrm{~b}^{+} \mathrm{LyC}^{\text {hi }} \mathrm{Ly}_{6 \mathrm{G}}{ }^{\text {lo }}$ MDSC-M in tumors from mice treated with IL-12 cells compared with mock cells (Figure 8C). These changes were not observed at earlier time points such as day 3 and day 7 (data not shown).

The majority of myeloid-derived cells remaining within tumors of mice treated with IL-12 cells were a uniform population of $\mathrm{CD}_{11 \mathrm{~b}^{+}}$, Ly6C ${ }^{\text {Mid-hi, }}$ and Ly6G ${ }^{\text {hi }}$ cells (Figure 8C). Although the fractional percentage of these "double-positive" granulocytic cells appeared to be higher (Figure 8C), upon quantification, the absolute number of cells within tumors appeared to be unchanged (Figure 8D). We observed significant decreases in the number of $\mathrm{CD} 11 \mathrm{~b}^{+} \mathrm{F} 4 / 80^{\text {hi }}$ macrophages, $\mathrm{CD} 11 \mathrm{~b}^{+} \mathrm{CD} 11 \mathrm{c}^{\text {hi }}$ dendritic cells, and CD $11 b^{+}$LyC $^{\text {hi }}$ Ly6 $6 G^{\text {lo }}$ MDSC-M cells in tumors from mice treated with IL-12 cells compared with mock cells (Figure 8D). We additionally found that changes in the $\mathrm{CD} 11 \mathrm{~b}^{+}$myeloid-derived populations occurred only in tumors and not in the spleens of C57BL/6 mice treated with IL-12 cells (Supplemental Figure 7). Unresolved by these experiments were whether decreased numbers of cells possessing the flow cytometric parameters identifying them as myelomonocytic cell subsets represented death of these cross-presenting cells or whether it indicated altered cell differentiation or migration. However, the changes that we observed in myeloid-derived subpopulations were confined to areas where tumor antigen was present and were not a part of a generalized phenomenon.

The role for $\mathrm{CD}_{11 \mathrm{~b}^{+}}$, Ly6C $\mathrm{C}^{\mathrm{mid}-\mathrm{hi}}$, and Ly6 $\mathrm{G}^{\text {hi }}$ granulocytic cells within IL-12-treated tumors remains to be thoroughly explored. In light of recent studies highlighting the capability of polarizing tumor-infiltrating neutrophils to an N1 phenotype (36), we hypothesized that perhaps the functional profile of Ly $6 \mathrm{G}^{\text {hi }}$ cells within IL-12-treated tumors may be altered. Given our earlier findings highlighting the need for endogenous cells to secrete IFN- $\gamma$ 
A

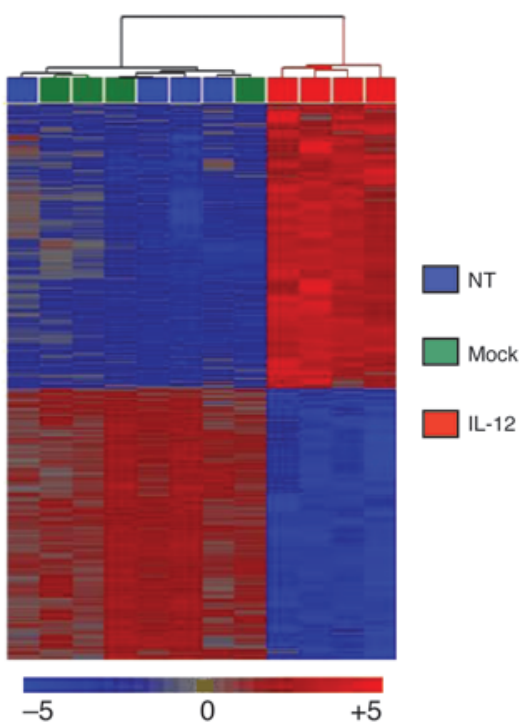

C

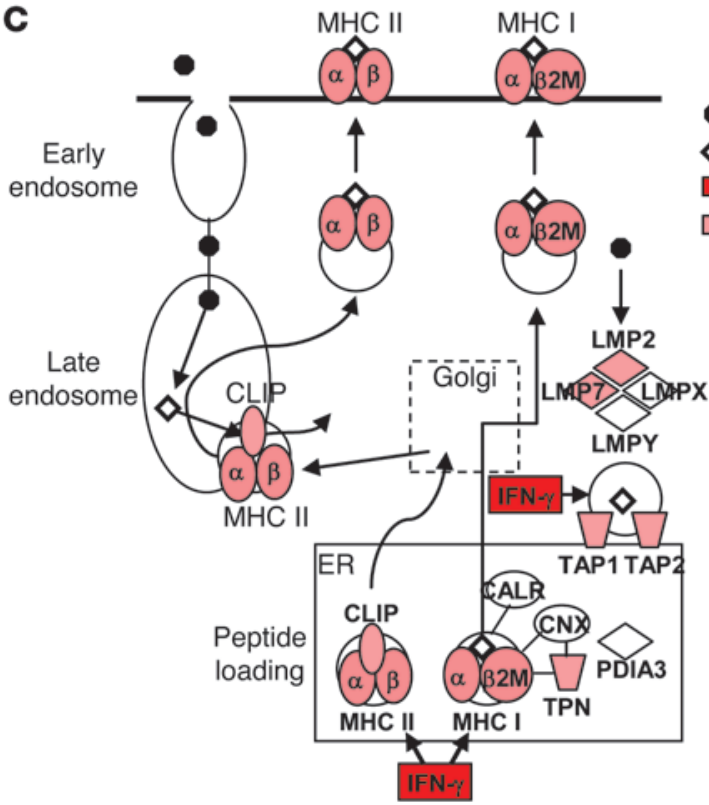

B

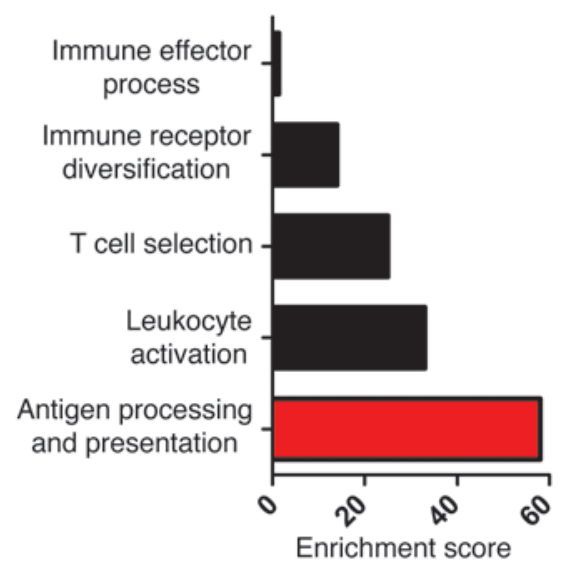

Polypeptide antigen

$\checkmark$ Processed peptide fragment

Upregulated (>10-fold)

Upregulated ( $>2$-fold)

\section{Figure 5}

Tumors from mice receiving IL-12 compared with mock cells display an increase in the intrinsic capabilities for antigen processing and presentation. (A) Dendrogram of whole transcriptome analysis displaying the 407 gene transcripts common to both day 3 and day 7 that were differentially expressed in tumors following the adoptive transfer of $10^{5} \mathrm{IL}-12$ cells compared with mock cells into sublethally irradiated mice bearing subcutaneous B16 tumors. Data are representative of 4 independent experimental samples. (B) Unbiased gene-ontology enrichment analysis for pathways under immune system processes from tumors of mice sublethally irradiated and treated with $10^{5} \mathrm{IL}-12 \mathrm{compared}$ with mock cells. Pathway analysis formulated using Ingenuity software. (C) Expression pattern (FC) from tumors of mice treated with IL-12 over mock cells for different gene transcripts involved in the antigen-processing and -presentation pathway. Data were generated using Ingenuity software analysis. (D) The top 8 upregulated and downregulated gene transcripts from tumors of mice treated with $10^{5} \mathrm{IL}-12$ over mock cells from A. Data represent mean \pm SEM of the FC from 4 independent samples. For $\mathbf{A}-\mathbf{D}$, differentially expressed genes were identified by 1 -way repeated measures ANOVA $(P<0.01)$ corrected by Benjamini-Hochberg FDR method $(P<0.05)$, and this gene list was further filtered for between-group $\alpha$ levels of $P<0.01$ and an FC criterion of more than 2.0 for genes differentially expressed from tumors treated with IL-12 over mock cells.

(Figure 3), we performed an intracellular stain for IFN- $\gamma$ in addition to staining for the different myeloid surface markers. We found that CD $11 b^{+}$Ly6G $\mathrm{G}^{\text {mid-hi }}$ cells, but not CD11b ${ }^{+}$Ly $6 \mathrm{G}^{\text {lo }}$ cells, from tumors of mice treated with IL-12 compared with mock cells, showed an increase in the ability to secrete IFN- $\gamma$ (Supplemental Figure 8).
All experiments described so far were preceded by a 5-Gy TBI preconditioning regimen. To determine whether this pretreatment preparation in some manner had an impact on the observed in vivo effects of IL-12, we transferred IL-12 cells into nonirradiated $\mathrm{Cd} 4^{-/-}$mice bearing B16 tumors and compared antitumor efficacy 
A

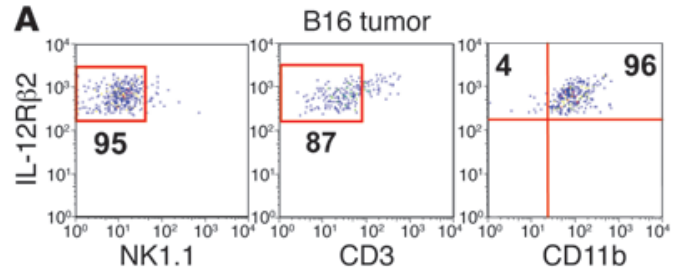

C

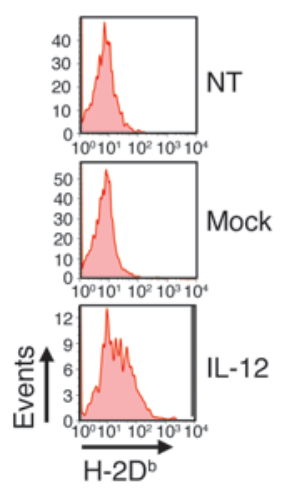

$\underline{\text { CD11b }^{+} \text {cells }}$
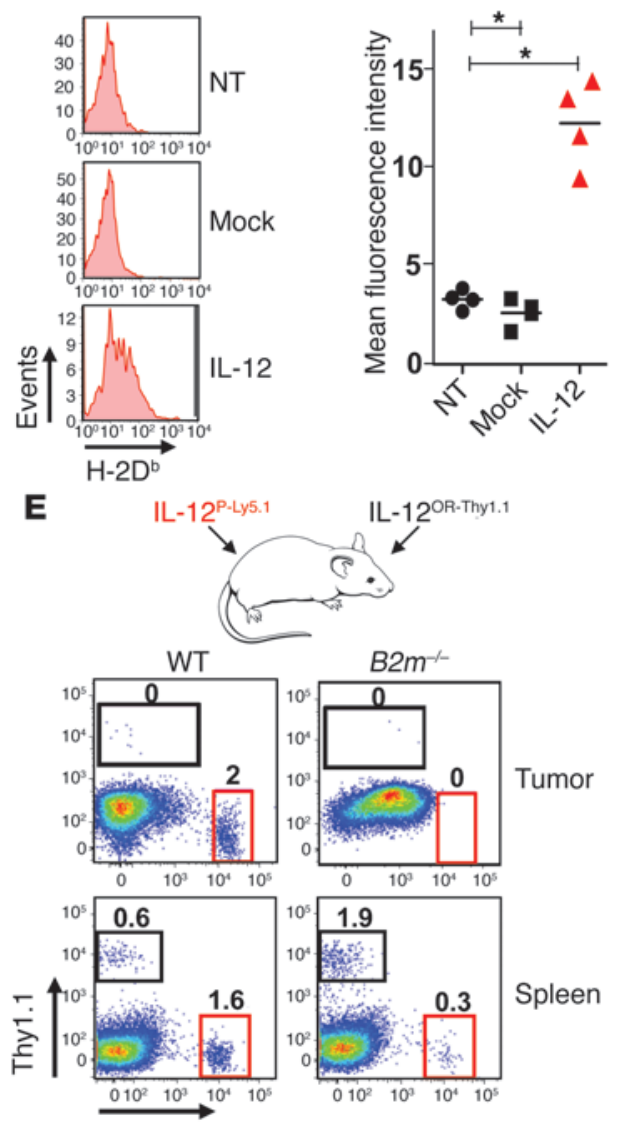

Ly 5.1
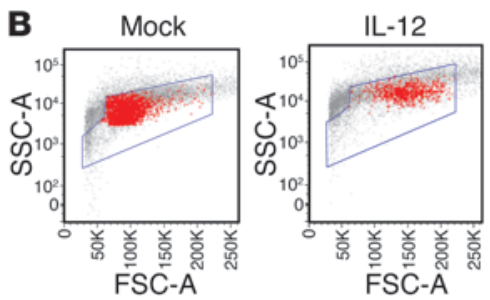

$\mathrm{PI}^{-}$

CD3-

B220-

NK1.1-

CD11 $\mathrm{b}^{+}$

D

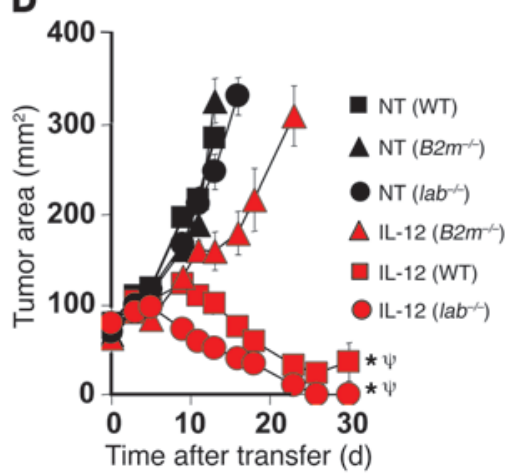

$\mathbf{F}$

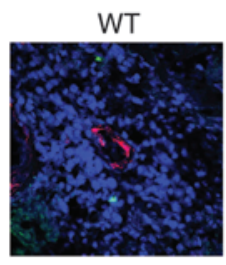

$\mathrm{B} 2 \mathrm{~m}^{-1-}$

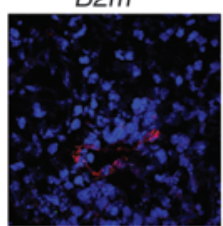

Figure 6

Enhanced antitumor immunity triggered by $\mathrm{LL}-12$ is dependent on in vivo cross presentation of tumor antigens. (A) The percentage of $\mathrm{PI}$, NK1.1-, CD3-, CD11 b+, and IL-12R $\beta 2^{+}$cells from single-cell suspensions of well-established B16 tumors. (B) Flow cytometric analysis with backgating for $\mathrm{PI}^{-} \mathrm{CD} 3-\mathrm{B} 220^{-} \mathrm{NK} 1.1^{-} \mathrm{CD} 11 \mathrm{~b}^{+}$cells from tumors 7 days following treatment with $10^{5} \mathrm{IL}-12$ or mock cells. (C) CD11b+ cells from B were examined for expression of $\mathrm{H}-2 \mathrm{D}^{\mathrm{b}}$ with quantification of mean fluorescence intensity for 4 independent mice (right panel). ${ }^{\star} P<0.05$, $t$ tests compared with no treatment. All plots are representative of at least 3 independent experiments. (D) Antitumor immunity in sublethally irradiated $\mathrm{WT}$, lab-/-, or B2m-/ C57BL/6 mice bearing established B16 tumors and treated with $10^{5} \mathrm{IL}-12$ cells. All data are expressed as mean \pm SEM and are representative of 2 independent experiments. ${ }^{*} P<0.05$, Wilcoxon's rank-sum test compared with no treatment control; ${ }^{\Psi} P<0.05$, compared with IL-12 cells into $B 2 \mathrm{~m}^{-/}$host. (E) Representative flow cytometry plots for transferred T cells in tumors and spleens harvested from sublethally irradiated WT or B2m-/- C57BL/6 mice 7 days following the transfer of $10^{5} \mathrm{IL}-12-$ expressing pmel-1 Ly5.1+CD8 ${ }^{+} \mathrm{T}$ cells $\left(\right.$ IL-12 $2^{\mathrm{P}-\mathrm{Ly} 5.1)}$ and $10^{5} \mathrm{IL}-12-$-expressing open-repertoire thy $1.1^{+} \mathrm{CD} 8^{+} \mathrm{T}$ cells $\left(\mathrm{IL}-12^{\mathrm{OR}}\right.$-Thy 1.1$)$ into the same mouse. Data are representative of 3 independent samples. Numbers represent percentage of Thy 1.1+Ly5.1- or Thy1.1-Ly5.1+ cells. (F) Confocal microscopy for tumor sections from mice treated in $\mathbf{D}$ (Thy1.1, green; CD31, red; DAPI, blue). Original magnification, $\times 40$.

to that of WT mice that received the 5-Gy TBI pretreatment. We observed identical antitumor responses between irradiated WT mice and nonirradiated $C d 4^{-/}$mice, indicating that the effects of IL-12 on myeloid cells were independent of pretreatment regimens that were necessary to remove $\mathrm{CD} 4^{+} \mathrm{T}$ cell populations acting as immune suppressors or sinks (Supplemental Figure 9). We sought to further measure whether irradiation contributed to the effects of IL-12 on tumor-infiltrating myeloid-derived populations in vivo. We transferred cells into nonirradiated Rag $1^{-/-}$mice and once again observed a decrease in the number of CD $11 b^{+} F 4 / 80^{\text {hi }}$ macrophages, $\mathrm{CD} 11 \mathrm{~b}^{+} \mathrm{CD} 11 \mathrm{c}^{\text {hi }}$ dendritic cells, and $\mathrm{CD} 11 \mathrm{~b}+\mathrm{Ly} 6 \mathrm{C}^{\text {hi }} \mathrm{Ly} 6 \mathrm{G}^{\text {lo }}$ MDSC-M in tumors from mice 14 days following treatment with 
A

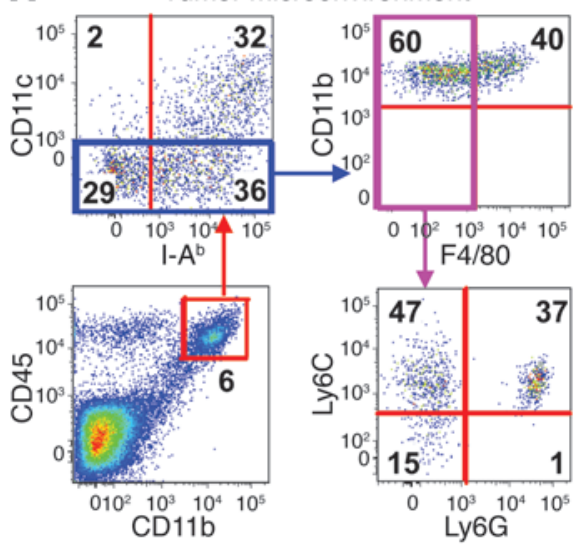

B

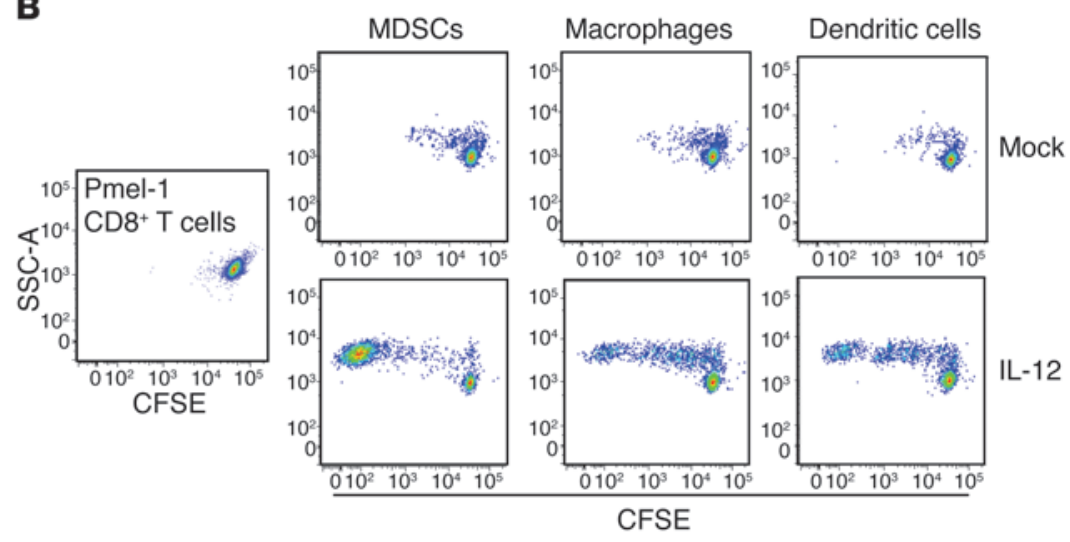

Figure 7

MDSCs, macrophages, and dendritic cells residing within B16 tumors of mice treated with IL-12 cells potently stimulate the proliferation of pmel CD8 ${ }^{+}$T cells. (A) B16 tumors established on C57BL/6 mice for 10 days were excised 8 hours following 5-Gy TBI and examined by multicolor flow cytometry for CD45, NK1.1, TCRb, B220, CD11b, CD11c, I-Ab, F4/80, Ly6C, and Ly6G cells. Flow cytometry plot is representative of at least 3 independent samples and gated on live, NK1.1-, TCRb-, and B220- cells. Numbers represent percentage of cells within each quadrant. (B) Single-cell tumor suspensions were created 5 days following treatment of established B16 tumors with IL-12 or mock cells, and CD11b+GR1hi MDSCs, CD11b+F4/80 hi macrophages, and CD11b+CD11 $\mathrm{c}^{\text {hi }}$ dendritic cells were sorted by flow cytometry and cocultured for 72 hours with CFSElabeled untouched pmel CD8+ T cells at a 10:1 T cells/APC ratio. Flow cytometry plots represent 3 independent samples.

IL-12 cells compared with mock cells (Supplemental Figure 10). Overall, these experiments show the importance of IL-12 for enhancing the in vivo cross presentation of tumor antigens, a mechanism independent of NKp46 innate lymphoid cells (Supplemental Figure 11), and suggest that the functional reprogramming of stromal cells such as macrophages, dendritic cells, and MDSCs plays an important role in the regression of established melanomas (Figure 9).

\section{Discussion}

Solid tumors form complex masses composed of diverse populations of cells. Intriguingly, they closely resemble lymphoid structures consisting of a full gamut of inflammatory immune cells, such as macrophages, dendritic cells, granulocytic cells, and immature myeloid cells $(3,37)$. However, unlike immune cells found within lymphoid organs that productively respond to acute infections, cells residing within tumors are alternatively activated and bathe in an immunosuppressive environment $(4,6,9)$.

Overcoming immune escape mechanisms induced by established tumors remains a critical barrier for tumor immunologists devising methods to combat cancer $(6,38-40)$. Lymphodepleting chemotherapy regimens are effective in removing regulatory $\mathrm{T}$ cells that act like sinks for homeostatic mediators, such as IL-7 and IL-15, and are a major source of suppressive cytokines, such as IL-10 and TGF- $\beta(19,41,42)$. Immune evasion in cancer, however, extends far beyond regulatory $\mathrm{T}$ cells, and multiple studies have highlighted the suppressive role of alternatively activated macrophages, functionally impaired dendritic cells, and MDSCs $(4,6,9,17)$.

Therapies to stimulate the immune system against cancer date back to over a century ago, when William B. Coley made the initial observation that tumors could regress after the administration of a mixture of bacteria consisting of killed cultures of Streptococci and Bacillus prodigiosus known as Coley's toxins. More recently, several clinical trials have tried to recapitulate these effects by administering proinflammatory cytokines against metastatic cancer with limited success $(21,43,44)$. One of the major barriers with the systemic administration of immunostimulatory mediators such as IL-12 is likely the inability to reach high enough local concentrations within tumors to impart a meaningful effect on resident immune cells (45).

Studies by Steven A. Rosenberg's group for the first time safely infused gene-modified lymphocytes into patients with metastatic cancer (46-48). In this study, we show that adoptively transferring tumor antigen-specific $\mathrm{CD}^{+} \mathrm{T}$ cells engineered to secrete IL-12 can functionally remodel the tumor microenvironment into an activated inflammatory state. These profound changes dramatically improved the ability of $\mathrm{CD}^{+} \mathrm{T}$ cells to mediate tumor regression. In contrast with much of the literature ascribing the benefits of IL-12 and IFN- $\gamma$ to unmasking the immunogenicity of tumor cells (49), we surprisingly show that IL-12 reversed immune escape mechanisms orchestrated by MDSCs, dysfunctional dendritic cells, and alternatively activated macrophages within the tumor microenvironment. Furthermore, these changes enabled improved function of activated $\mathrm{CD}^{+} \mathrm{T}$ cells, implying that the recognition of crosspresented cognate antigen in the presence of an acute inflammatory environment had direct effects on tumor regression.

This study also suggests that direct recognition and targeting of the tumor stroma may be critical for attaining regression of large vascularized lesions (12-14). When we adoptively transferred in vitro-activated tumor-specific IL-12-expressing $\mathrm{CD}^{+} \mathrm{T}$ cells into mice deficient in MHC class I, we witnessed dramatic impairments in antitumor responses, even though mice had unmanipulated B16 tumors fully capable of presenting antigen to T cells. Furthermore, IL-12-expressing $\mathrm{CD}^{+} \mathrm{T}$ cells $\left(\mathrm{H}-2^{\mathrm{b}}\right.$ restricted) were able to cause the regression of Cloudman $\mathrm{S} 91$ melanomas $\left(\mathrm{H}-2^{\mathrm{d}}\right.$ restricted) in C57BL/ $6 \times$ DBA F1 $\left(\mathrm{H}-2^{\mathrm{b} / \mathrm{d}}\right)$ mice, indicating that even in the absence of direct recognition of tumor cells, significant regression of established lesions could occur. The likely mechanism for $\mathrm{CD}^{+}$ $\mathrm{T}$ cell destruction of established lesions may be multi-fold, but our study, along with others, indicates that the collapse of the tumor 
A

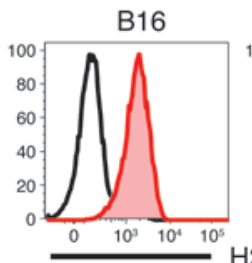

Cloudman S91
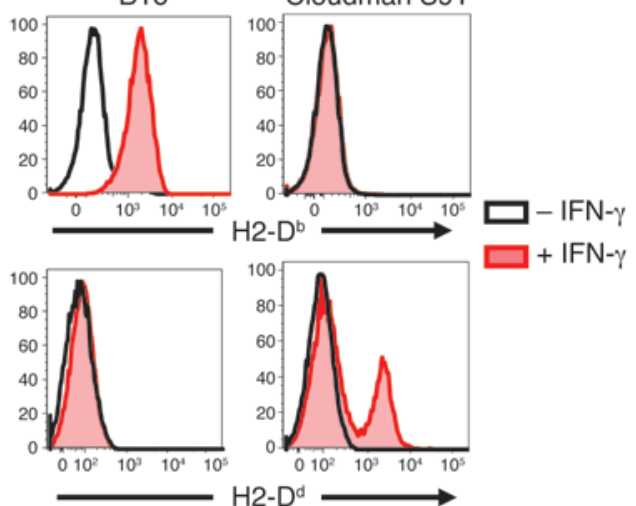

+ IFN- $\gamma$

C

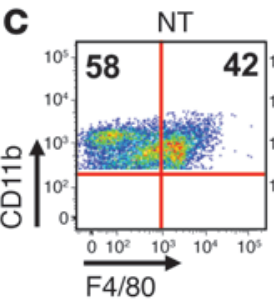

Mock
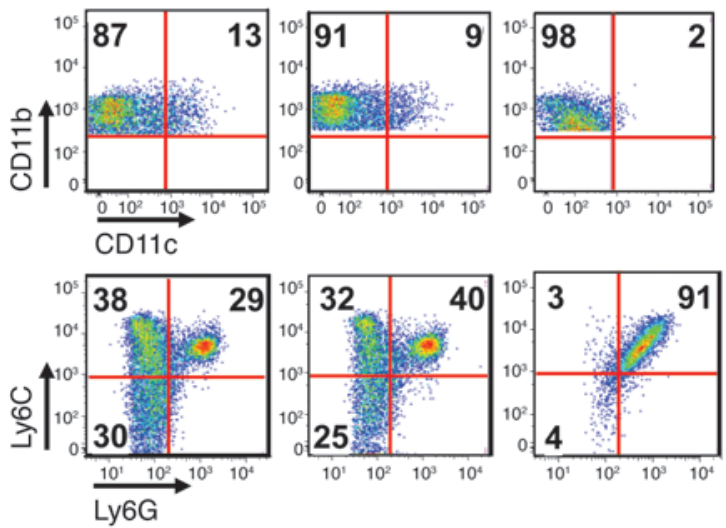

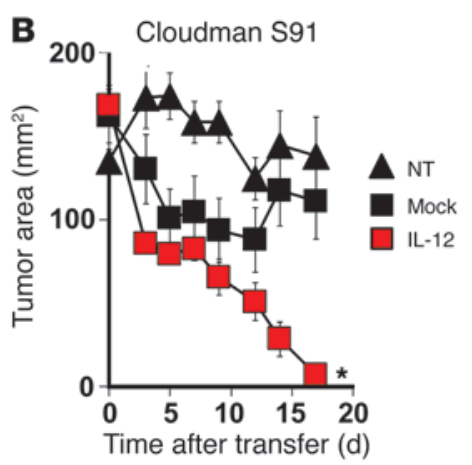

D

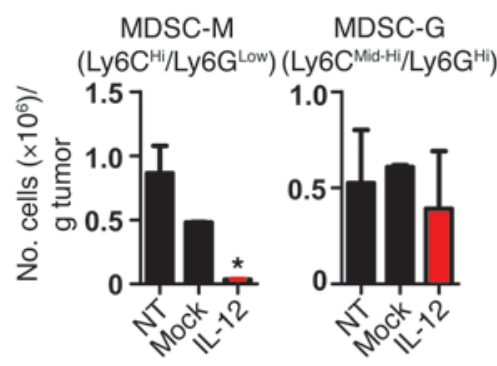

Dendritic cells $\left(\mathrm{CD} 11 \mathrm{~b}^{+} / \mathrm{CD} 11 \mathrm{C}^{\mathrm{Hi}}\right)$

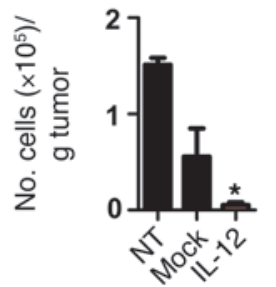

Macrophages $\left(\mathrm{CD}_{11 \mathrm{~b}}+\mathrm{F} 4 / 80^{\mathrm{HI}}\right)$

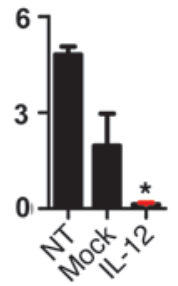

\section{Figure 8}

IL-12 cells $\left(\mathrm{H}-2^{\mathrm{b}}\right)$ are capable of causing complete regression of established Cloudman S91 melanomas $\left(\mathrm{H}-2^{\mathrm{d}}\right)$ on $\mathrm{C} 57 \mathrm{BL} / 6 \times$ DBA F1 mice $\left(\mathrm{H}-2^{\mathrm{b} / \mathrm{d}}\right)$. (A) $\mathrm{H}-2 \mathrm{D}^{\mathrm{b}}$ and $\mathrm{H}-2 \mathrm{D}^{d}$ expression of $\mathrm{B} 16$ and Cloudman S91 melanoma cell lines exposed to $675 \mathrm{ng} / \mathrm{ml}$ of IFN- $\gamma$ for 48 hours. (B) Antitumor immunity of $5 \times 10^{5} \mathrm{IL}-12$ or mock cells adoptively transferred into sublethally irradiated C57BL/ $6 \times \mathrm{DBA}$ $\mathrm{F} 1 \mathrm{H}-2^{\mathrm{b} / \mathrm{d}}$ mice bearing subcutaneous Cloudman S91 tumors established for 21 days. All data are expressed as mean \pm SEM and are representative of 2 independent experiments. ${ }^{*} P<0.05$, Wilcoxon's rank-sum test compared with no treatment and mock. (C) Flow cytometry plots for macrophages (CD11 b+ F4/80 hi), dendritic cells (CD11b+CD11 $c^{\text {hi }}$ ), MDSC-M (CD11b+Ly6ChilLyGlo), and MDSC-G (CD11b+Ly6C Mid-hi Ly6Gi) within established Cloudman S91 melanomas on $\mathrm{C} 57 \mathrm{BL} / 6 \times \mathrm{DBA} \mathrm{F} 1 \mathrm{H}-2^{\mathrm{b} / \mathrm{d}}$ mice 10 days following treatment with IL-12 or mock cells. All plots gated on $\mathrm{PI}$ - live cells; numbers represent percentage of cells in each quadrant. (D) Data from $\mathbf{C}$ were quantified through a flow cytometry count and normalized to 1 gram of tumor. Data are expressed as mean \pm SEM. ${ }^{*} P<0.05,1$-way ANOVA compared with NT and mock controls. stroma along with its intertwined vasculature may be a critical determining factor preceding tumor regression (16).

Following successful treatment with IL-12 cells, we witnessed a complete remodeling of the tumor microenvironment and the disappearance of Ly6 $\mathrm{C}^{\text {hi }}$ Ly $6 \mathrm{G}^{\mathrm{lo}} \mathrm{MDSCs}$, macrophages, and dendritic cells within regressing lesions 10 days following cell transfer. Although these studies suggest that adoptively transferred IL-12-expressing $\mathrm{CD}^{+} \mathrm{T}$ cells recognize and target cross-presenting myeloid populations, we cannot rule out the possibility that these findings may be due to altered differentiation, homing to, or egress of myeloid cells from the tumor site.

Another concept that may help explain some of the findings in this manuscript is bystander killing (16). Adoptively transferred $\mathrm{CD}^{+} \mathrm{T}$ cells may initially recognize cross-presented cognate antigen by myeloid-derived cells, and the collapse of the surrounding stroma and tumor cells requires bystander effects. Interestingly, we observed regression of established tumors $1 \mathrm{~cm}$ in size (approximately $10^{9}$ cell), although the number of antigen-specific $\mathrm{T}$ cells infiltrating the tumor never exceeded $10^{5}$ cells. Immunofluorescence staining further showed that the number of transferred $\mathrm{T}$ cells were far outnumbered by cells composing the tumor mass. Further studies will need to be completed in order to understand the complex interac- tions happening within the tumor microenvironment leading to $\mathrm{T}$ cell-mediated regression of established lesions.

In summary, we demonstrate what we believe is a novel mechanism for IL-12 in antitumor immunity. IL-12 at the tumor site dramatically reversed local immune evasion mechanisms by altering the intrinsic capabilities of professional APCs residing within the tumor stroma. This programmatic change in myeloid-derived cells within tumors enabled direct recognition of cross-presented cognate antigen by $\mathrm{CD}^{+} \mathrm{T}$ cells. Designing $\mathrm{T}$ cells capable of penetrating and altering the tightly coordinated tumor microenvironment may dramatically improve future adoptive immunotherapy clinical trials and enable current gene therapies to reach their full therapeutic potential against cancer (50-55). The findings generated from this study have formed the basis for a clinical trial accruing patients at the time of this writing at the National Cancer Institute (NCI) at the NIH. Patients with metastatic melanoma will receive IL-12-engineered tumor-infiltrating lymphocytes (TILs) following a lymphodepleting chemotherapy regimen (ClinicalTrials.gov ID NCT01236573).

\section{Methods}

Mice and tumor lines. Female thy1.1+ P-TCR Tg mice were generated in our laboratory (50) and made available at The Jackson Laboratory. Female 


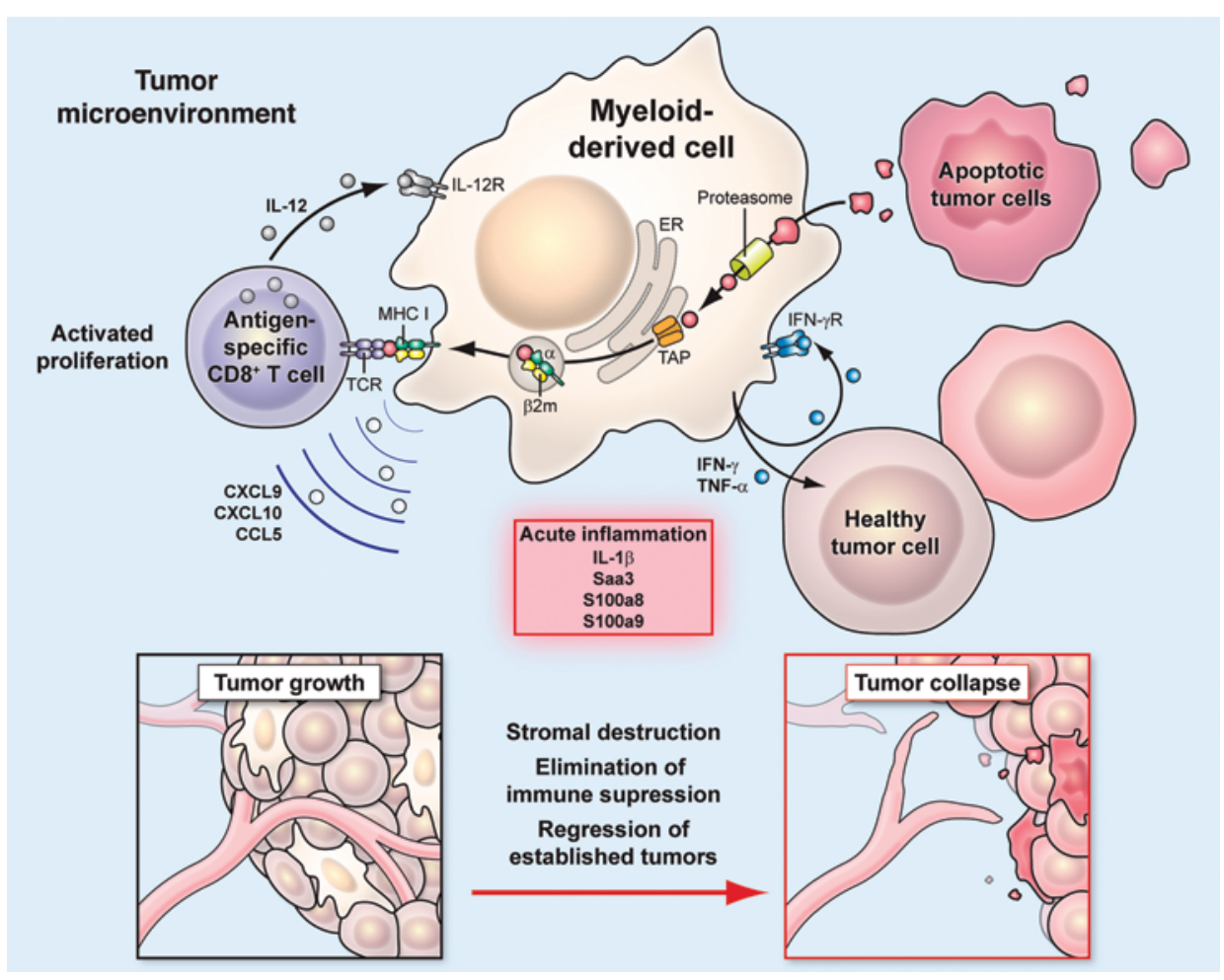

Figure 9

Schematic diagram summarizing the proposed mechanism for tumor destruction induced by IL-12. Myeloid-derived cells within the tumor microenvironment are sensitized by IL-12 to create an acute inflammatory environment and improve the ability of antigen-specific CD8 ${ }^{+} \mathrm{T}$ cells to collapse large established tumors.

cells were analyzed by flow cytometry for thy1.1 and CD8 $\alpha$ expression.

Accurate enumeration was accomplished through flow cytometry counts. Two-hundred microliters of the singlecell tumor suspension, initially in an enzymatic mixture volume of $10 \mathrm{ml}$, were stained with the appropriate antibodies, and the entire $200 \mu \mathrm{l}$ sample was run through a CANTO II Flow Cytometry Machine (BD Biosciences) to obtain a digital count that could be evaluated using FlowJo software (Tree Star Inc.). Real-time RT-PCR was performed as previously described (42).

Flow cytometry cell sorts for $\mathrm{PI}^{-}, \mathrm{NK}^{-}$, B220-, CD3-, CD $11 b^{+}, C^{-} 11 b^{+}$Gr- $1^{\text {hi }}$, $\mathrm{CD} 11 \mathrm{~b}^{+} \mathrm{CD} 11 \mathrm{c}^{\mathrm{hi}}$, and $\mathrm{CD} 11 \mathrm{~b}^{+} \mathrm{F} 4 / 80^{\mathrm{hi}}$ cells from single-cell tumor suspensions were performed using a FACSAria II cell sorter (BD Biosciences). Sorted cells were lysed using RLT buffer (QIAGEN), and RNA was isolated using the RNeasy Mini Kit (QIAGEN). For in vitro proliferation assays, untouched $\mathrm{CD}^{+} \mathrm{T}$ cells isolated (Miltenyi Biotec) from spleens of pmel-1 mice were labeled with $1 \mu \mathrm{M}$ of CFSE and cocultured for 72 hours with different myeloid populations isolated from tumors in a 10:1 T cell/APC ratio.

RT-PCR arrays (SABiosciences) for known genes in the antigen-presentation and -processing pathway were used to analyze functional reprogramming of $\mathrm{CD} 11 \mathrm{~b}^{+}$

C57BL/6 mice, C57BL/6 CD90.1 (thy1.1 ${ }^{+}$), C57BL/6 Cd4 $4^{-/}, \mathrm{C} 57 \mathrm{BL} / 6 \mathrm{Rag}^{-/-}$,

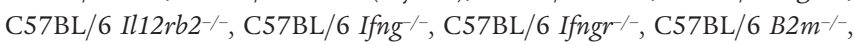
$\mathrm{C} 57 \mathrm{BL} / 6 \mathrm{IAb}^{-/}$, and $\mathrm{C} 57 \mathrm{BL} / 6 \times \mathrm{DBA} \mathrm{F} 1 \mathrm{H}-2^{\mathrm{b} / \mathrm{d}}$ mice were obtained from The Jackson Laboratory. C57BL/ 6 female ly5.1 $1^{+}$mice were crossed with female C57BL/6 P-TCR Tg mice to generate ly5.1+ P-TCR Tg mice. C57BL/6 female Il12rb2- $2^{--}$mice were crossed with female C57BL/6 P-TCR Tg mice to generate Il12rb2-- P-TCR Tg mice. Tumor lines used for in vivo experiments included B16, an $\mathrm{H}-2^{\mathrm{b}+} / \mathrm{gp} 100^{+}$murine melanoma, and Cloudman S91, an $\mathrm{H}-2^{\mathrm{d}^{+}} / \mathrm{gp} 100^{+}$murine melanoma (56). Both tumor lines were purchased from ATCC and established and maintained as previously described (57).

Retroviral production and transduction. Detailed descriptions of gene therapy protocols for mice have been previously described (58).

Adoptive cell transfer. A detailed description of cell transfer methodology is described in the Supplemental Methods.

Analysis of transferred and tumor-infiltrating cells: flow cytometry, cell enumeration, flow cytometry sorts, CFSE proliferation, RT-PCR arrays, real-time PCR, and IL-12p70 ELISA. Prior to transfer, $\mathrm{CD}^{+} \mathrm{T}$ cells were characterized by flow cytometry for CD8 $\alpha$, CD62L, CD44, IL-7R $\alpha$, IL-2R $\alpha$, and Sca-1 (BD Biosciences). IL-12, IFN- $\gamma$, and TNF- $\alpha$ were analyzed using intracellular staining kits (BD Biosciences) with or without a 4-hour stimulation with phorbol myristate acetate (PMA) $(50 \mathrm{ng} / \mathrm{ml})$ and ionomycin $(1 \mu \mathrm{g} / \mathrm{ml}$; Sigma-Aldrich). Following adoptive transfer, tumor samples were harvested, digested with $200 \mathrm{U} / \mathrm{ml}$ collagenase IV (Invitrogen) and $100 \mu \mathrm{g} / \mathrm{ml}$ DNAse I (Roche), and evaluated by flow cytometry for B220, NK1.1, CD3, TCRb, CD45, CD45.1 (ly5.1), CD90.1 (thy1.1), CD11b, F4/80, Ly6C, Ly6G, CD11c, I- $\mathrm{A}^{\mathrm{b}}, \mathrm{H}-2 \mathrm{D}^{\mathrm{b}}$, and H-2Dd (BD Biosciences). Transferred pmel-thy $1.1^{+}$ cells from tumors treated with IL-12 compared with mock cells. Single-gene RT-PCR assays and ELISAs were performed as previously described (42).

Whole genome expression analysis and immunofluorescent confocal microscopy. Please refer to Supplemental Methods for detailed description (GEO GSE29164).

Statistics. Tumor growth slopes were compared using Wilcoxon's ranksum test. All data are represented as mean \pm SEM. One-way ANOVA and 2 -tailed Student $t$ tests were used to test for significant differences in enumeration assays. $P<0.05$ was considered significant.

Study approval. All experiments were conducted with the approval of the NCI Animal Use and Care Committee.

\section{Acknowledgments}

This research was supported by the Intramural Research Program of the NIH, NCI, Center for Cancer Research. The authors would like to thank Dorina Frasheri, Arnold Mixon, and Shawn Farid for excellent technical assistance and Megan Bachinski for editorial checks.

Received for publication May 2, 2011, and accepted in revised form September 28, 2011.

Address correspondence to: Sid P. Kerkar or Nicholas P. Restifo, National Cancer Institute, National Institutes of Health, Room 3-5762, 10 Center Drive, Bethesda, Maryland 20892-1502, USA. Phone: 301.496.6507; Fax: 301.451.6949; E-mail: kerkars@mail. nih.gov (S.P. Kerkar); restifon@nih.gov (N.P. Restifo). 
1. Coussens LM, Werb Z. Inflammation and cancer. Nature. 2002;420(6917):860-867.

2. Ostrand-Rosenberg S, Sinha P. Myeloid-derived suppressor cells: linking inflammation and cancer. J Immunol. 2009;182(8):4499-4506.

3. Hanahan D, Weinberg RA. Hallmarks of cancer: the next generation. Cell. 2011;144(5):646-674

4. Mantovani A, Sica A. Macrophages, innate immunity and cancer: balance, tolerance, and diversity. Curr Opin Immunol. 2010;22(2):231-237.

5. Huang AY, Golumbek P, Ahmadzadeh M, Jaffee E, Pardoll D, Levitsky H. Role of bone marrow-derived cells in presenting MHC class I-restricted tumor antigens. Science. 1994;264(5161):961-965.

6. Gabrilovich DI, Nagaraj S. Myeloid-derived suppressor cells as regulators of the immune system. Nat Rev Immunol. 2009;9(3):162-174

7. Gabrilovich DI, et al. Production of vascular endothelial growth factor by human tumors inhibits the functional maturation of dendritic cells. Nat Med. 1996;2(10):1096-1103

8. Bronte $\mathrm{V}$, et al. Apoptotic death of CD8+ T lymphocytes after immunization: induction of a suppressive population of Mac-1+/Gr-1+ cells. JImmunol. 1998; 161(10):5313-5320.

9. Bronte V. Myeloid-derived suppressor cells in inflammation: uncovering cell subsets with enhanced immunosuppressive functions. Eur J Immunol. 2009;39(10):2670-2672.

10. Mapara MY, Sykes M. Tolerance and cancer: mechanisms of tumor evasion and strategies for breaking tolerance. J Clin Oncol. 2004;22(6):1136-1151.

11. Lu T, et al. Tumor-infiltrating myeloid cells induce tumor cell resistance to cytotoxic T cells in mice. J Clin Invest. 2011;121(10):4015-4029.

12. Zhang B, et al. Equilibrium between host and cancer caused by effector $T$ cells killing tumor stroma. Cancer Res. 2008;68(5):1563-1571.

13. Zhang B, Karrison T, Rowley DA, Schreiber H. IFNgamma- and TNF-dependent bystander eradication of antigen-loss variants in established mouse cancers. J Clin Invest. 2008;118(4):1398-1404.

14. Zhang B, et al. Induced sensitization of tumor stroma leads to eradication of established cancer by T cells. J Exp Med. 2007;204(1):49-55

15. Wigginton JM, Wiltrout RH. IL-12/IL-2 combination cytokine therapy for solid tumours: translation from bench to bedside. Expert Opin Biol Ther. 2002;2(5):513-524.

16. Spiotto MT, Rowley DA, Schreiber H. Bystander elimination of antigen loss variants in established tumors. Nat Med. 2004;10(3):294-298.

17. Serafini $\mathrm{P}$, et al. Phosphodiesterase-5 inhibition augments endogenous antitumor immunity by reducing myeloid-derived suppressor cell function. J Exp Med. 2006;203(12):2691-2702.

18. Gajewski TF, et al. Immune resistance orchestrated by the tumor microenvironment. Immunol Rev. 2006; 213:131-145

19. Antony PA, et al. CD8+ T cell immunity against a tumor/self-antigen is augmented by CD4+ T helper cells and hindered by naturally occurring $\mathrm{T}$ regulatory cells. I Immunol. 2005;174(5):2591-2601.

20. Finke J, Ko J, Rini B, Rayman P, Ireland J, Cohen P. MDSC as a mechanism of tumor escape from sunitinib mediated anti-angiogenic therapy. Int Immunopharmacol. 2011;11(7):856-861.

21. Weiss JM, Subleski JJ, Wigginton JM, Wiltrout RH. Immunotherapy of cancer by IL-12-based cytokine combinations. Expert Opin Biol Ther. 2007;
7(11):1705-1721

22. Trinchieri G. Interleukin-12 and the regulation of innate resistance and adaptive immunity. Nat Rev Immunol. 2003;3(2):133-146.

23. Colombo MP, Trinchieri G. Interleukin-12 in antitumor immunity and immunotherapy. Cytokine Growth Factor Rev. 2002;13(2):155-168.

24. Brunda MJ, et al. Antitumor and antimetastatic activity of interleukin 12 against murine tumors. J Exp Med. 1993;178(4):1223-1230.

25. Eisenring M, vom Berg J, Kristiansen G, Saller E, Becher B. IL-12 initiates tumor rejection via lymphoid tissue-inducer cells bearing the natural cytotoxicity receptor NKp46. Nat Immunol. 2010; 11(11):1030-1038.

26. Szabo SJ, Sullivan BM, Stemmann C, Satoskar AR, Sleckman BP, Glimcher LH. Distinct effects of Tbet in TH1 lineage commitment and IFN-gamma production in CD4 and CD8 T cells. Science. 2002; 295(5553):338-342.

27. Takemoto N, Intlekofer AM, Northrup JT, Wherry EJ, Reiner SL. Cutting Edge: IL-12 inversely regulates T-bet and eomesodermin expression during pathogen-induced CD8 $+\mathrm{T}$ cell differentiation. Jimmunol. 2006;177(11):7515-7519.

28. Smyth MJ, Taniguchi M, Street SE. The anti-tumor activity of IL-12: mechanisms of innate immunity that are model and dose dependent. J Immunol. 2000;165(5):2665-2670.

29. Nastala CL, et al. Recombinant IL-12 administration induces tumor regression in association with IFN-gamma production. J Immunol. 1994; 153(4):1697-1706.

30. Bhardwaj N, Seder RA, Reddy A, Feldman MV. IL-12 in conjunction with dendritic cells enhances antiviral CD8+CTL responses in vitro. J Clin Invest. 1996;98(3):715-722.

31. Mazzolini $G$, et al. Intratumoral injection of dendritic cells engineered to secrete interleukin-12 by recombinant adenovirus in patients with metastatic gastrointestinal carcinomas. J Clin Oncol. 2005;23(5):999-1010.

32. Kerkar SP, et al. Tumor-specific CD8+ T cells expressing interleukin-12 eradicate established cancers in lymphodepleted hosts. Cancer Res. 2010;70(17):6725-6734.

33. Zhang $\mathrm{L}$, et al. Improving adoptive $\mathrm{T}$ cell therapy by targeting and controlling IL-12 expression to the tumor environment. Mol Ther. 2011;19(4):751-759.

34. Gabrilovich DI, et al. The terminology issue for myeloid-derived suppressor cells. Cancer Res. 2007; $67(1): 425$.

35. Movahedi K, et al. Identification of discrete tumorinduced myeloid-derived suppressor cell subpopulations with distinct $\mathrm{T}$ cell-suppressive activity. Blood. 2008;111(8):4233-4244.

36. Fridlender ZG, et al. Polarization of tumor-associated neutrophil phenotype by TGF-beta: "N1" versus "N2" TAN. Cancer Cell. 2009;16(3):183-194.

37. Kowanetz M, et al. Granulocyte-colony stimulating factor promotes lung metastasis through mobilization of Ly6G+Ly6C+ granulocytes. Proc Natl Acad Sci US A. 2010;107(50):21248-21255.

38. Peranzoni E, et al. Myeloid-derived suppressor cell heterogeneity and subset definition. Curr Opin Immunol. 2010;22(2):238-244.

39. Mocellin S, Marincola FM, Young HA. Interleukin-10 and the immune response against cancer: a counterpoint. J Leukoc Biol. 2005;78(5):1043-1051. 40. Hurwitz AA, et al. Combination immunotherapy of primary prostate cancer in a transgenic mouse model using CTLA-4 blockade. Cancer Res. 2000; 60(9):2444-2448.

41. Mackall CL, Hakim FT, Gress RE. Restoration of T-cell homeostasis after T-cell depletion. Semin Immunol. 1997;9(6):339-346.

42. Gattinoni L, et al. Removal of homeostatic cytokine sinks by lymphodepletion enhances the efficacy of adoptively transferred tumor-specific CD8+ T cells. J Exp Med. 2005;202(7):907-912.

43. Leonard JP, et al. Effects of single-dose interleukin-12 exposure on interleukin-12-associated toxicity and interferon-gamma production. Blood. 1997;90(7):2541-2548.

44. Gollob JA, et al. Phase I trial of concurrent twice-weekly recombinant human interleukin12 plus low-dose IL-2 in patients with melanoma or renal cell carcinoma. J Clin Oncol. 2003; 21(13):2564-2573.

45. Kilinc MO, et al. Reversing tumor immune suppression with intratumoral IL-12: activation of tumorassociated $\mathrm{T}$ effector/memory cells, induction of $\mathrm{T}$ suppressor apoptosis, and infiltration of CD8+ T effectors. J Immunol. 2006;177(10):6962-6973.

46. Rosenberg SA, et al. Gene transfer into humans-immunotherapy of patients with advanced melanoma, using tumor-infiltrating lymphocytes modified by retroviral gene transduction. $N$ Engl J Med. 1990;323(9):570-578.

47. Morecki S, et al. Retrovirus-mediated gene transfer into CD4+ and CD8+ human $\mathrm{T}$ cell subsets derived from tumor-infiltrating lymphocytes and peripheral blood mononuclear cells. Cancer Immunol Immunother. 1991;32(6):342-352.

48. Blaese RM, et al. T lymphocyte-directed gene therapy for ADA- SCID: initial trial results after 4 years. Science. 1995;270(5235):475-480.

49. Dighe AS, Richards E, Old LJ, Schreiber RD. Enhanced in vivo growth and resistance to rejection of tumor cells expressing dominant negative IFN gamma receptors. Immunity. 1994;1(6):447-456.

50. Morgan RA, et al. Cancer regression in patients after transfer of genetically engineered lymphocytes. Science. 2006;314(5796):126-129.

51. June CH, Blazar BR, Riley JL. Engineering lymphocyte subsets: tools, trials and tribulations. Nat Rev Immunol. 2009;9(10):704-716.

52. Hwu P, Rosenberg SA. The genetic modification of T cells for cancer therapy: an overview of laboratory and clinical trials. Cancer Detect Prev. 1994; 18(1):43-50.

53. Brenner MK, Heslop HE. Adoptive T cell therapy of cancer. Curr Opin Immunol. 2010;22(2):251-257.

54 . Barrett AJ, Le Blanc K. Immunotherapy prospects for acute myeloid leukaemia. Clin Exp Immunol. 2010; 161(2):223-232.

55. Sadelain M. T-cell engineering for cancer immunotherapy. Cancer J. 2009;15(6):451-455.

56 . Wagner $\mathrm{SN}$, et al. Intracutaneous genetic immunization with autologous melanoma-associated antigen Pmel17/gp100 induces T cell-mediated tumor protection in vivo. J Invest Dermatol. 2000;115(6):1082-1087.

57. Overwijk WW, et al. Tumor regression and autoimmunity after reversal of a functionally tolerant state of self-reactive CD8+ T cells. J Exp Med. 2003; 198(4):569-580.

58. Kerkar SP, et al. Genetic engineering of murine $\mathrm{CD} 8+$ and $\mathrm{CD} 4+\mathrm{T}$ cells for preclinical adoptive immunotherapy studies. J Immunother. 2011; 34(4):343-352. 